\title{
Rupture Directivity Characteristics of the 2003 Big Bear Sequence
}

\author{
by Ying Tan and Don Helmberger
}

\begin{abstract}
We have developed a forward modeling technique to retrieve rupture characteristics of small earthquakes $(3<M<5)$, including rupture propagation direction, fault dimension, and rupture speed. The technique is based on an empirical Green's function (EGF) approach, where we use data from collocated smaller events as Green's functions to study the bigger events. We tend to choose smaller events with similar focal mechanisms for EGFs; however, we show that the events with different focal mechanisms can work equally well when corrected for radiation pattern effect. Compared to deconvolution, this forward modeling approach allows full use of both the shape and amplitude information produced by rupture propagation. Assuming a simple 1D source model, we parameterize the source time function of a target event as the convolution of two boxcars, featuring the rise time $\tau_{r}$ and the rupture time $\tau_{c}$; we solve for $\tau_{r}$ and $\tau_{c}$ in a grid search manner by minimizing the waveform misfit between the three-component data and the synthetics constructed from the EGFs. The rupture propagation direction, fault length, and rupture speed can then be estimated by fitting the observed azimuthal pattern of $\tau_{c}$ from $P$ and $S$ waves. We apply the approach to the 12 largest events $\left(M_{\mathrm{w}} \geq 3.3\right)$ of the 2003 Big Bear sequence (excluding the mainshock) in southern California. Among them, seven events are found to exhibit robust rupture directivity. The fact that the ruptures of these events propagate in all directions reveals complicated fault geometry at depth. We compute the stress drop $\Delta \sigma \sim \frac{2}{\pi} \frac{M_{0}}{L^{3}}$ for each event using the resolved fault length. The results show large variations ranging from $\sim 1$ to $90 \mathrm{Mpa}$, with no dependence on moment. However, $\Delta \sigma$ appears inversely correlated with rupture speed $V_{r}$; in particular, events with larger $\Delta \sigma$ tend to propagate at smaller $V_{r}$, whereas events with smaller $\Delta \sigma$ propagate faster.
\end{abstract}

\section{Introduction}

Directivity due to the rupture propagation on the fault plane is an important characteristic of many earthquakes. Retrieving rupture directivity of a seismic event can help understand the fault structure by telling the real fault plane from a focal mechanism solution (e.g., Mori, 1993; Venkataraman et al. 2000; Boatwright, 2007), as well as improve hazard analysis, such as shaking estimates (e.g., Aagaard et al., 2008). Besides, the derived source parameters such as fault dimension, rupture speed, and stress drop can provide valuable data for studying the physics of earthquakes (e.g., Frankel and Kanamori, 1983; McGuire, 2004; Kanamori and Rivera, 2004). While retrieving the detailed slip distribution model of large events $(M>5)$ is becoming a routine process (e.g., Ji et al., 2002), the characterization of smaller events remains a particular challenge. Because their fault lengths are generally less than a few hundred meters, the analysis has to be conducted at high frequencies (e.g., $>8 \mathrm{~Hz}$ ), where an adequate velocity model is normally unavailable and the unmodeled structural effect can easily contaminate the source signal.
A common practice under such circumstances is the empirical Green's function (EGF) approach (e.g., Hartzell, 1978; Frankel and Kanamori, 1983; Mori, 1993; Ammon et al., 1993; Hough and Dreger, 1995; Fletcher and Spudich, 1998; Lanza et al., 1999; McGuire, 2004; de Lorenzo et al., 2008). The EGF approach assumes a large event and a smaller EGF event occur at a similar location and have a similar focal mechanism, so that they share nearly the same propagational effect, and a linear scaling between their source terms exists at the same stations. Therefore, the relative source time functions (RSTFs) of the large event can be obtained by simply deconvolving the EGFs from its records at high frequencies. On the other hand, at longer periods where the details of the events' source processes can be ignored, and both events can be approximately modeled with simple triangular source time functions, the large event with well-determined source mechanism can be used to calibrate the path effect for studying the smaller event. In a recent article by Tan and Helmberger (2007), we have developed such a technique to retrieve focal mechanisms of small events 
$(M<4)$, where we used well-determined long-period solutions of magnitude $\sim 4$ events to progressively calibrate the path effects, mainly amplitude corrections on high frequency $P$ waves so that smaller events can be well modeled. Using this approach, we have determined over 90 focal mechanism solutions of events with $M_{L}$ down to 2.0 from the $2003 \mathrm{Big}$ Bear sequence. Figure 1 displays a subset that will be discussed in this article. These accurate focal mechanism solutions enable us to choose the most appropriate EGF event for studying the detailed rupture processes of the larger ones. Such an example is displayed in Figure 2, where the simple $P$-wave amplitude ratios between the two events can be used as a robust indicator of rupture directivity. Even in an extreme case where an EGF event with a similar source mechanism cannot be found, we can generate EGFs of the desired source mechanism using radiation pattern corrections. Figure 3 displays such feasibility, where we successfully map the $P$-wave portion of one small event into that of another at all azimuths, simply by multiplying the ratio of the $P$-wave radiation patterns inferred from synthetics.
Given such accuracy in the source mechanism solutions, we propose a new forward modeling approach in this article to retrieve rupture directivity of the larger events in the 2003 Big Bear sequence, which can fully utilize both duration and amplitude information produced by rupture propagation. Particularly, the amplitude information has been ignored in many previous studies that use a deconvolution technique (e.g., Hough and Dreger, 1995; Lanza et al., 1999; McGuire, 2004), due to the fact that noise or small differences in the two events' mechanisms or locations can easily introduce large errors in the shape and amplitude of the retrieved RSTFs. Figure 4 displays a particular example of retrieving RSTFs using the Projected Landwebber Deconvolution approach developed by Lanza et al. (1999). This iterative method with positivity constraint in time domain has proved effective in many previous studies (e.g., Lanza et al., 1999; McGuire, 2004), and we have followed their procedures. Although the durations of the RSTFs appear constant, the large difference in their shapes and amplitudes presents difficulty in interpreting the results. These complexities are

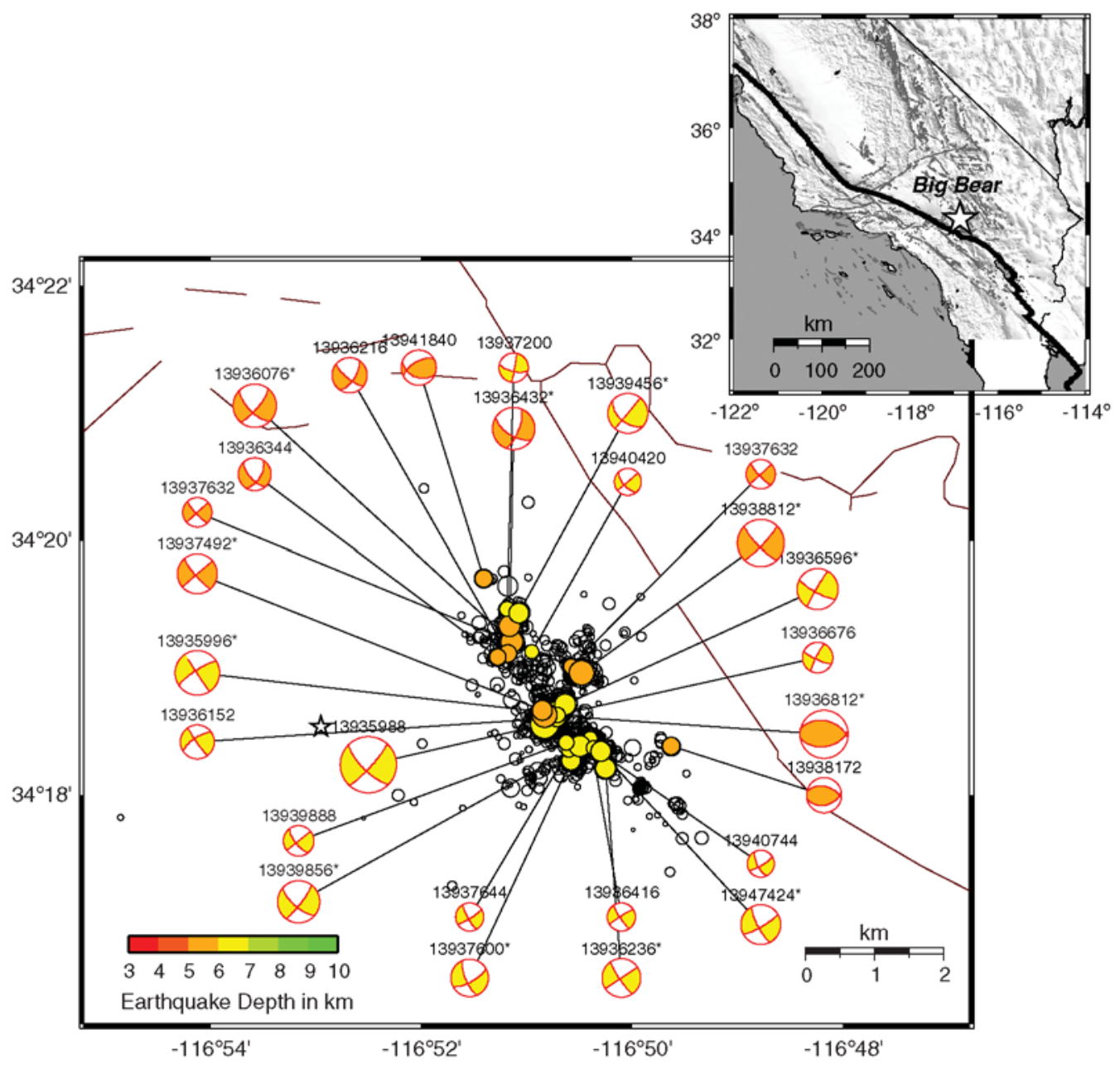

Figure 1. Selected source mechanism solutions on top of the 2003 Big Bear sequence from Tan and Helmberger (2007). The event locations are from Chi and Hauksson (2006) with a double-difference approach. The main event is indicated with an open star. The 12 events with an asterisk $(*)$ are studied in this article and displayed together with the chosen EGF events. 


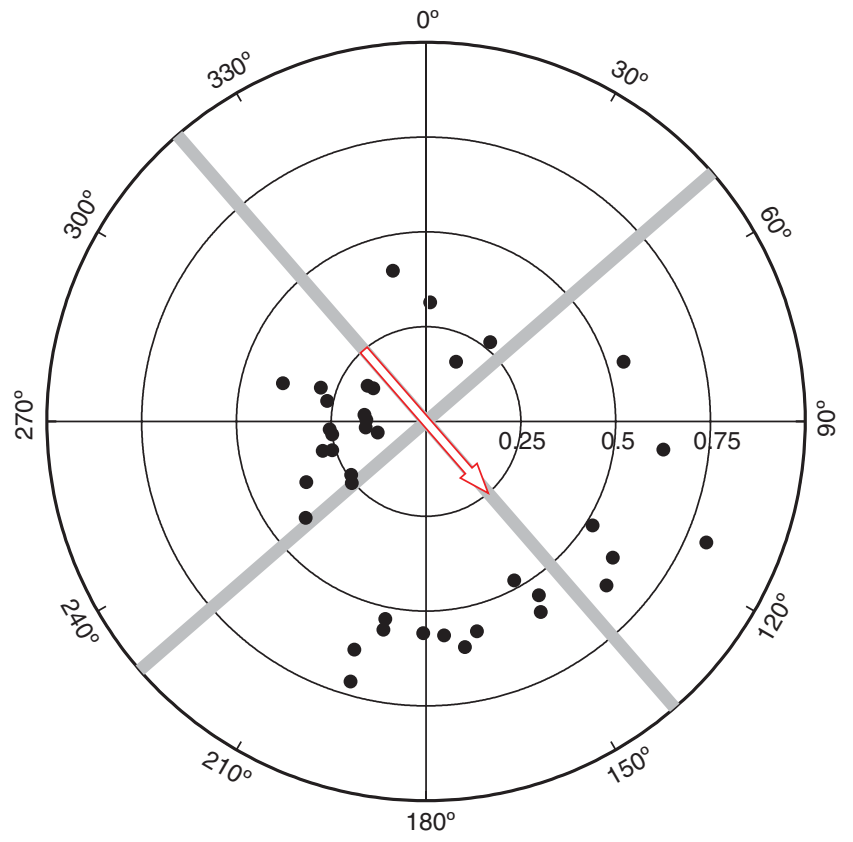

Figure 2. The vertical $P$-wave amplitude ratios, $A m_{7632} /$ $\mathrm{Amp}_{7492}$, between the events $13937632(M \sim 2.5)$ and 13937492 $(M \sim 3.5)$. The two events have similar strike-slip focal mechanisms (Fig. 1). The gray lines indicate the strikes of the fault planes from the focal mechanism solution. Note the amplitude ratios for the southeastern stations are consistently larger than those for the northwestern stations, suggesting that the rupture of event 13937492 propagates toward the southeast. A similar attempt was made in a recent article by Boatwright (2007) using strong motion recordings.

mainly due to noise contamination and fine scale structural effect.

To mitigate the effects of these small uncertainties, we assume a priori trapezoid shape of the RSTFs according to the simple Haskell source model (Haskell, 1964), and solve for the rise time $\tau_{r}$ and rupture time $\tau_{c}$ in a forward modeling process. With the resolved $\tau_{r}$ and $\tau_{c}$, the fault length $(f l)$ and rupture speed $\left(V_{r}\right)$ can be easily obtained. In the following sections, we will first introduce the methodology and then describe the applications on the 2003 Big Bear sequence. In particular, we will focus on the 12 largest events $\left(M_{\mathrm{w}}>3.3\right)$, excluding the mainshock in the cluster, where the smaller events with nearly the same source mechanisms, but magnitudes at least one unit less can be chosen for the EGFs (see Fig. 1). The results and implications will be discussed afterward.

\section{Methodology}

Let $d(t)$ and $g(t)$ be the records from a target event and the associated EGF event at the same station, which can be related by the relative source time function, $\operatorname{RSTF}(t)$ of the large event as:

$$
d(t)=g(t) * \operatorname{RSTF}(t) .
$$

If the source duration of the EGF event is short enough to approximate a delta function, the resolved $\operatorname{RSTF}(t)$ of the large event will be approximately equal to its true source time function (STF). Assuming a simple trapezoidal shape of the $\operatorname{STF}(t)$ according to the 1D Haskell model (Haskell, 1964), it can be parameterized as the convolution of two boxcars, featuring the rise time $\tau_{r}$ and the rupture time $\tau_{c}$; we can solve for $\tau_{r}$ and $\tau_{c}$ in a grid search manner by minimizing the misfit defined as:

$$
e=\left\|d(t)-\Delta M_{0} g(t) * \operatorname{STF}(t)\right\|,
$$

where

$$
\operatorname{STF}(t)=\tau_{r}(t) * \tau_{c}(t)
$$

Here the parallels denote the $L_{2}$ norm. $\Delta M_{0}$ is an amplitude scaling factor to account for the two events' difference in size and radiation pattern. In practice, a good estimate from a station is obtained only when the cross-correlation value between $d(t)$ and $\Delta M_{0} g(t) * \mathrm{STF}(t)$ is over 80, plus their $\log$ amplitude ratio is within $(-0.2,0.2)$. Note that there is perfect trade-off between $\tau_{r}$ and $\tau_{c}$ when they are solved for a single station. However, because $\tau_{r}$ should be the same for all the stations according to the 1D source assumption, we can obtain the best value of $\tau_{r}$ when the summation of misfit errors from all the stations,

$$
e^{\prime}=\sum_{i=1}^{N} e_{i}\left(\tau_{r}, \tau_{c}\right)
$$

is minimized. The azimuthal variation of the corresponding $\tau_{c}$ s can then provide information on rupture directivity. For a simple scenario, where the rupture propagates unilaterally, the corresponding $\tau_{c}$ s can be approximately described by the following equation:

$$
\tau_{c}=\frac{f l}{V_{r}}-\frac{f l}{V_{P, S}} \vec{R} \cdot \vec{U}
$$

Here $f l$ and $V_{r}$ denote the fault length and rupture speed. $V_{P, S}$ is the $P$ - or $S$-wave phase velocity in the source region. $\vec{R}$ and $\vec{U}$ represent the unit vectors of the rupture propagation and ray direction at the source. Because most stations that we use have take off angles close to $90^{\circ}$, that is, the rays leave the source nearly flat, equation (5) can be simplified as:

$$
\begin{aligned}
\tau_{c}= & \frac{f l}{V_{r}}-\frac{f l}{V_{P, S}}[\cos (\varphi-\phi) \cos (\lambda) \\
& -\sin (\varphi-\phi) \sin (\lambda) \cos (\delta)],
\end{aligned}
$$

where $\varphi$ is the station azimuth and $\phi$ is the strike of the rupture propagation direction. $\delta$ denotes the dip of the fault plane, and $\lambda$ represents the rupture propagation direction measured from horizontal. Note that in the bracket of equation (6), the contribution to $\tau_{c}$ has been separated into two parts, the first term comes from the horizontal component of 
(a)

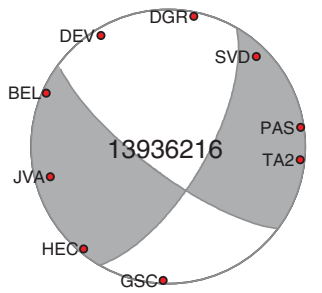

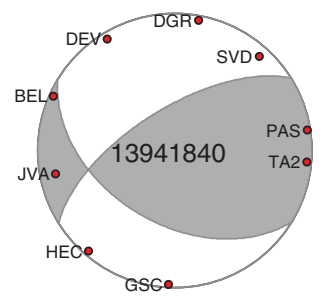

(b)

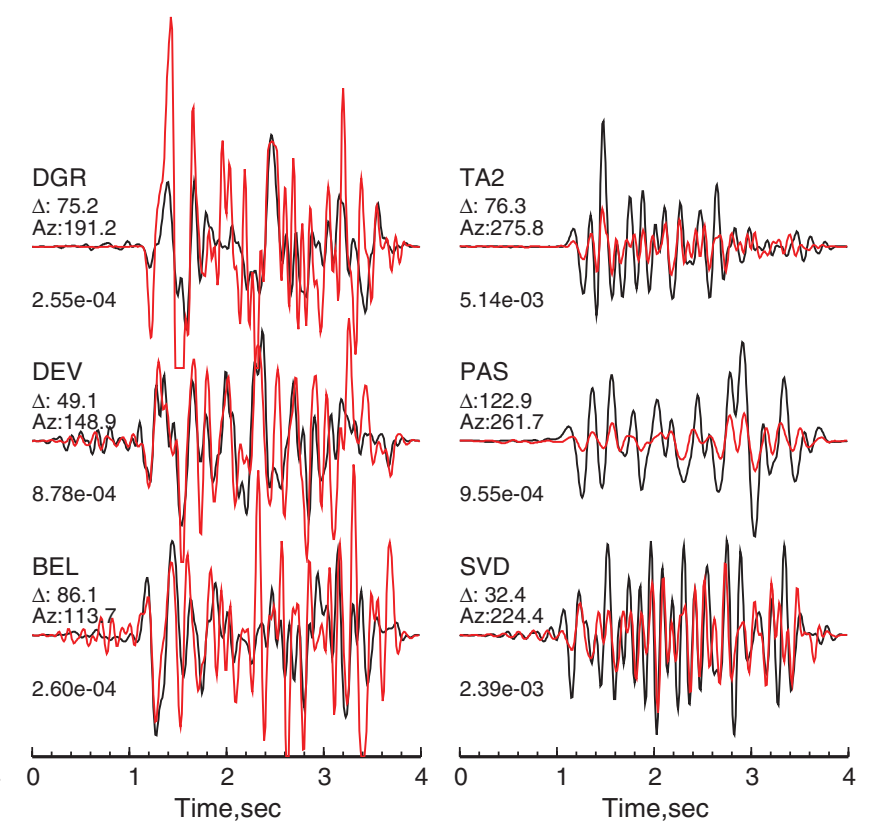

(c)
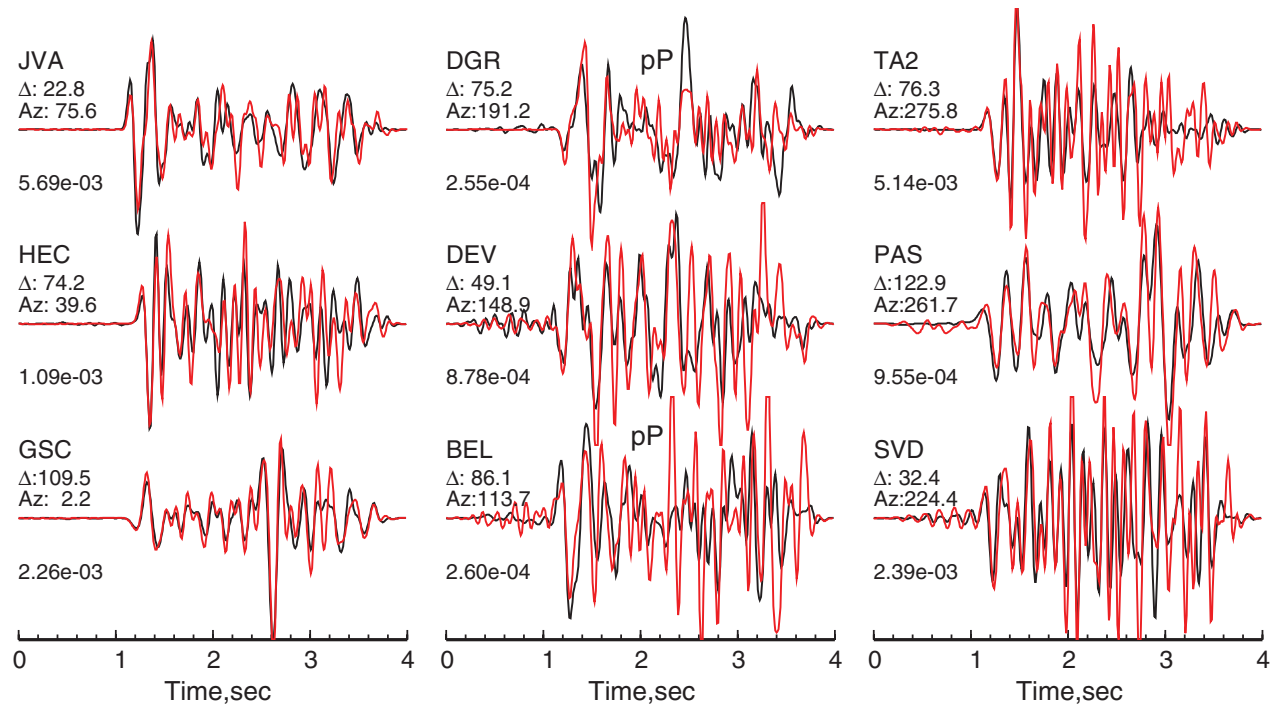

Figure 3. (a) The focal mechanisms of the strike-slip event (13936216) and the thrust event (13941840) together with the selected stations sampling the whole azimuthal range. Note that the two events have similar magnitudes $\sim 3.1$. The records from these stations of the two events (13936216: black; 13941840: red) will be compared in (b) and (c). A band-pass filter (0.5-10 Hz) has been applied and the amplitudes of the traces have been normalized by the factors below them. Particularly in (b), the records of the thrust event (13941840) have been multiplied by simple amplitude and polarity corrections derived from synthetics, to account for the two events' differences in radiation patterns.

rupture propagation, whereas the second term comes from the vertical component. Obviously, for events with nearly vertical fault planes, determining the vertical component of rupture propagation is impractical. So, for most events that we have studied with a dominant strike-slip mechanism (see Fig. 1), we are focused on determining the horizontal component of rupture propagation only. Simply by setting $\lambda$ equal to $0^{\circ}$, equation (6) can be further simplified as: 


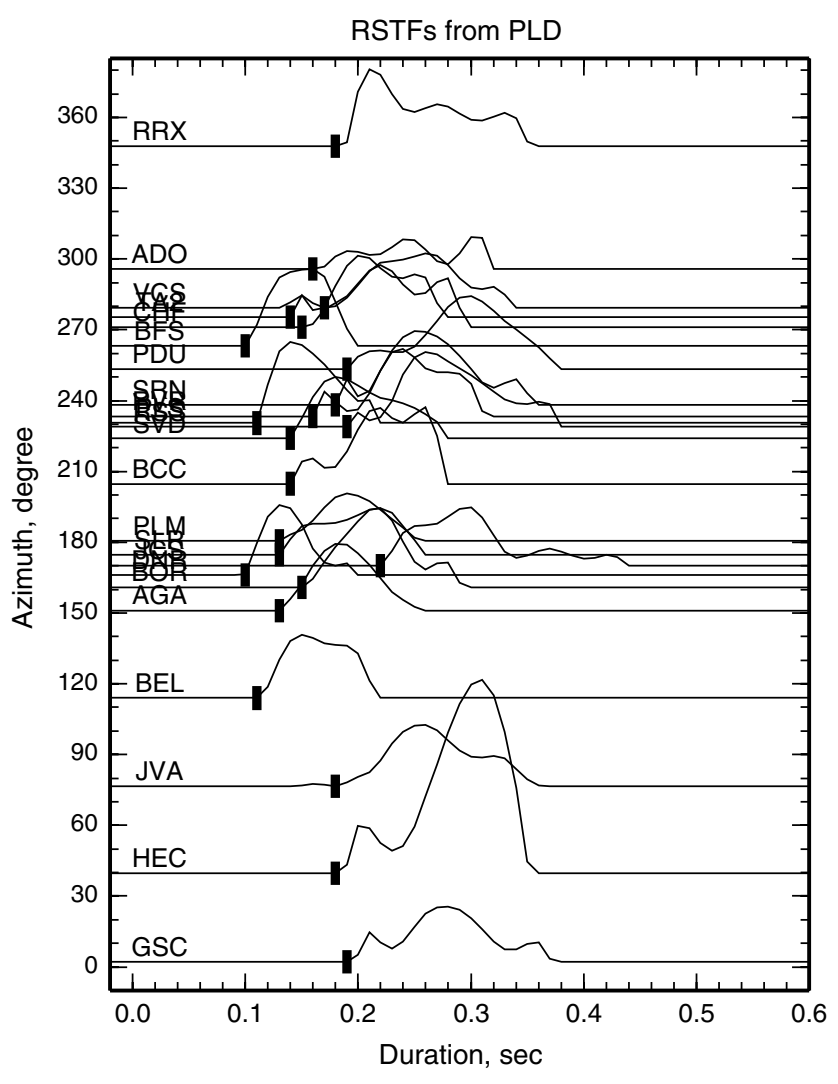

Figure 4. The relative source time functions (RSTFs) of event 13936432 in relation to the EGF event 13937200 obtained by deconvolution. The RSTFs are shifted so that their onsets are aligned with the black bars indicating their durations.

$$
\tau_{c}=\frac{f l}{V_{r}}-\frac{f l}{V_{P, S}} \cos (\varphi-\phi) .
$$

Next in this section, we will use event 13937492 to illustrate the whole process, where we will also briefly address the observed trade-off between $\tau_{r}$ and $\tau_{c}$, plus how it would affect the estimates of $f l$ and $V_{r}$. More results will be presented in the Results section where the attempt to resolve the vertical component of rupture propagation for the thrust event 13936812 and the bilateral rupture of event 13938812 is also included.

Event $13937492\left(M_{\mathrm{w}} \sim 3.5\right)$ is the most pronounced unilateral event among our studied events due to its largest fault length. It has a nearly pure strike-slip focal mechanism, and we have chosen a smaller event (13937632, $\left.M_{\mathrm{w}} \sim 2.5\right)$, which has almost the same focal mechanism (Tan and Helmberger, 2007) for the EGFs. We tend to choose events with magnitudes at least one unit smaller for EGFs, which has proved a good rule in many previous studies (e.g., Venkataraman et al., 2000; McGuire, 2004). Moreover, our earlier study (Tan, 2006) has revealed that the decrease of the source duration with decreasing magnitude levels off at $M_{\mathrm{w}} \sim 2.5$, suggesting the waveforms of such small events can be con- sidered as impulse response for studying larger events of the cluster. The two events are located within $500 \mathrm{~m}$ from each other (Chi and Hauksson, 2006). We use both $P$ and $S$ waves from the three-component data, and a band-pass filter of $0.5-$ $10 \mathrm{~Hz}$ has been applied to avoid rather small-scale rupture heterogeneities. We conduct the grid searches separately for $P$ and $S$ waves, because the corresponding $\tau_{c}$ s are different due to their different phase velocities. Figure 5a displays the total misfit error $e^{\prime}$ from all the stations versus $\tau_{r}$. $e^{\prime}$ reaches its minimum at $\tau_{r}=0.08 \mathrm{sec}$ for both $P$ and $S$ waves, although there is some uncertainty. The effect of choosing a different $\tau_{r}$, for example, the minimum value of $0.02 \mathrm{sec}$, on the estimates of $f l$ and $V_{r}$ will be addressed later in this section. The corresponding $\tau_{c} \mathrm{~s}$ for the individual stations are displayed in Figure 5b,c for $P$ wave and 5d,e for $S$ wave, where $\tau_{c}$ reaches a pronounced minimum at an azimuth of $\sim 140^{\circ}$. Such variations of $\tau_{c}$ can be directly verified with the waveform comparisons as displayed in Figure 6 for $P$ waves. The selected stations well sample the whole azimuthal range. Apparently, the stations GSC and ALP that are located opposite from the rupture propagation direction require the largest rupture times, whereas those stations located along the rupture propagation direction, such as BEL and SLR, need significantly shorter source time functions. A similar trend is observed for $S$ waves (Fig. 7), although their waveform fits are slightly poorer, due to more complexities. Note in both Figures 6 and 7 that the minimum rupture times, such as for the stations BEL, SLR, and SVD, are mainly resolved from amplitude comparisons.

We fit the observed $\tau_{c}$ s with equation (7) to estimate the fault length $(f l)$ and rupture velocity $\left(V_{r}\right)$ in two steps. First, we search for the best $\phi$ that produces the largest linear correlation coefficient between $\tau_{c}$ and $\Delta=\cos (\varphi-\phi)$; and then we determine the best $f l$ and $V_{r}$ by the linear leastsquares fit between $\tau_{c}$ and $\Delta$. Similar procedures were previously practiced by Courboulex et al. (1997). The best $\phi$ values from $P$ and $S$ waves almost coincide with the strike of the northwest-southeast fault plane of the focal mechanism solution. In addition, the azimuthal variation of $\tau_{c}$ indicates that the rupture is propagating toward the southeast, which is consistent with the earlier result using amplitude information alone (Fig. 2). By assuming a $P$ velocity of $6.0 \mathrm{~km} / \mathrm{sec}$ and an $S$ velocity of $3.5 \mathrm{~km} / \mathrm{sec}$, we obtain a fault length of $\sim 0.45 \mathrm{~km}$ and a relatively large rupture velocity of $\sim 3.6 \mathrm{~km} / \mathrm{sec}$ from $P$ waves (Fig. 5c), whereas the smaller values of $\sim 0.36 \mathrm{~km}$ for $f l$ and $\sim 3.0 \mathrm{~km} / \mathrm{sec}$ for $V_{r}$ are resolved from $S$ waves (Fig. 5e). To interpret such discrepancy between the $P$ - and $S$-wave result might be of limited value because the uncertainties in the $\tau_{c}$ measurements, especially those from $S$ waves, can introduce errors in the estimates of $f l$ and $V_{r}$. However, it is worth mentioning that the uncertainties of the $\tau_{c}$ s from $P$ waves are generally smaller than those from $S$ waves, due to the simpler $P$ waveforms. Hence, the $P$-wave result is more robust.

As we have mentioned earlier in Figure 5a, although $e^{\prime}$ reaches its minimum at $\tau_{r}=0.08 \mathrm{sec}$ for both $P$ and $S$ 
(a)

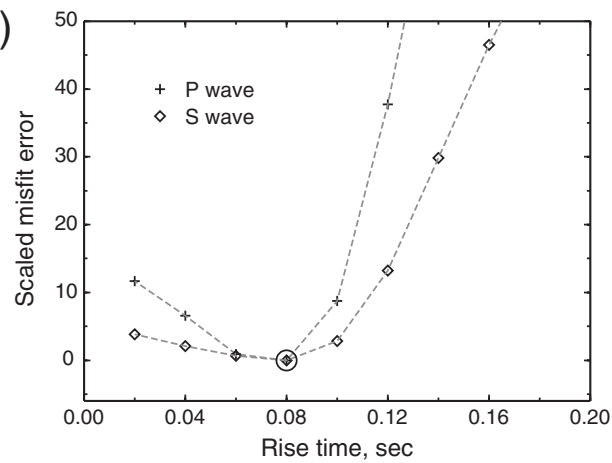

(b)

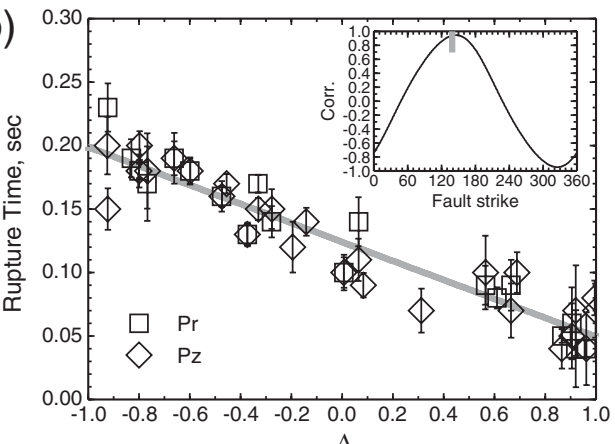

(d)

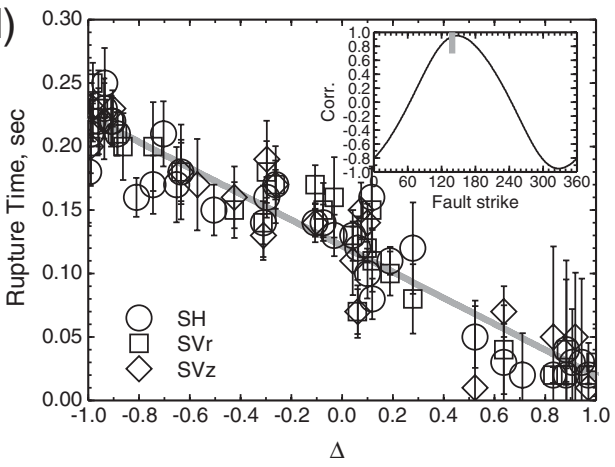

Main event
13937492(Mw:3.5)

EGF event 13937492(Mw:3.5) 13937632(Mw:2.5)

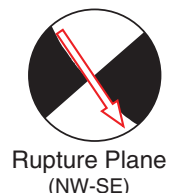

Directivity: Unilatera

(c)

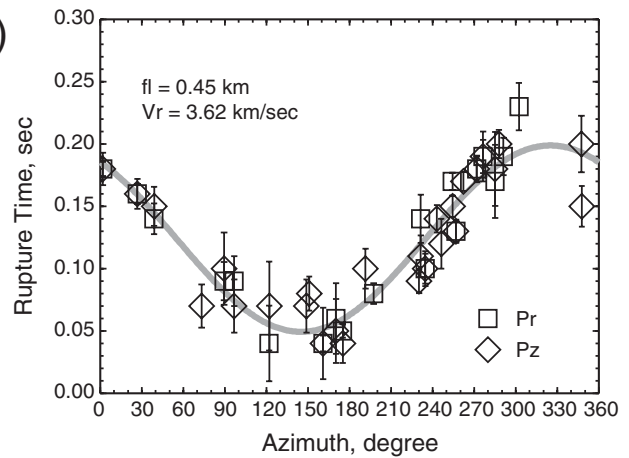

(e)

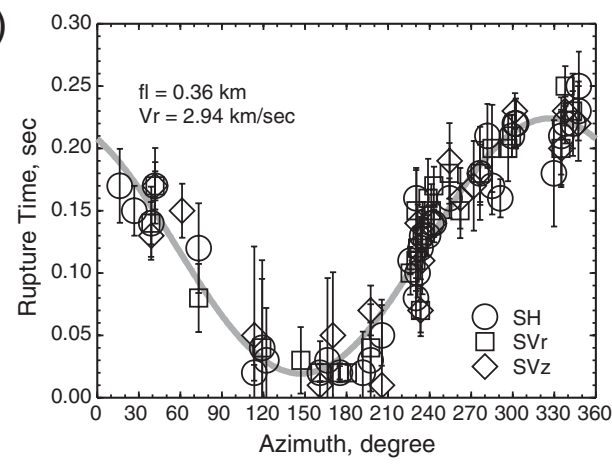

Figure 5. Rupture directivity result for event 13937492. (a) The summation of misfit errors as defined in equation (4) from all the stations scaled by their minima versus rise time $\tau_{r}$. The circle indicates where the $e$ 's reach the minima, and $\tau_{r}$ is selected. (b) The $\tau_{c}$ estimates from $P$ waves versus $\Delta\left(\Delta=\cos \left(\varphi-\phi_{0}\right)\right)$ with the preferred rupture direction $\phi_{0}$. $\phi_{0}$ is chosen where the linear correlation coefficient between $\tau_{c}$ and $\Delta$ reaches the maximum (see the inset, the gray bar indicates the fault strike from the focal mechanism solution). The plotted data points are associated with waveform cross-correlation values greater than 80 between the records from the main event (13937492) and the EGF event (13937632) convolved with the RSTFs. The uncertainties of the $\tau_{c} \mathrm{~s}$ are estimated by a $10 \%$ decrease in variance reduction. The gray line displays the linear least-squares fit between $\tau_{c}$ and $\Delta$, from which fault length $(f l)$ and rupture speed $\left(V_{r}\right)$ can be estimated. (c) $\tau_{c}$ versus azimuth. (d,e) display the results from $S$ waves.

waves, the resolution is poor. In particular, $e^{\prime}$ remains small for a wide range, $0.02-0.10 \mathrm{sec}$ of $\tau_{r}$. Choosing a different $\tau_{r}$ will not change the picture on rupture propagation; however, the estimated rupture speed will be affected due to the wellknown trade-off between $\tau_{r}$ and $V_{r}$ (e.g., Konca et al., 2007). In an effort to quantify the lower bound of rupture speed, Figure 8 displays the results for an extreme case, where the minimum $\tau_{r}$ of $0.02 \mathrm{sec}$ is assumed. As it might be predicted, the corresponding $\tau_{c}$ s generally become larger to compensate for the trapezoid shape change. Accordingly, the resolved rupture speed becomes smaller due to the ele- vated $\frac{f l}{V_{r}}$. Note that the $f l$ estimate remains nearly the same, whereas the $V_{r}$ estimate becomes slightly slower from $P$ waves. However, the effect appears more severe on the $S$ wave result due to the larger uncertainties in resolving $\tau_{r}$ and $\tau_{c}$ from $S$ waves.

\section{Results}

We have applied the approach to the 12 largest events $\left(M_{\mathrm{w}}>3.3\right)$ of the 2003 Big Bear sequence (Fig. 1), excluding the mainshock. The main event was discarded because the 


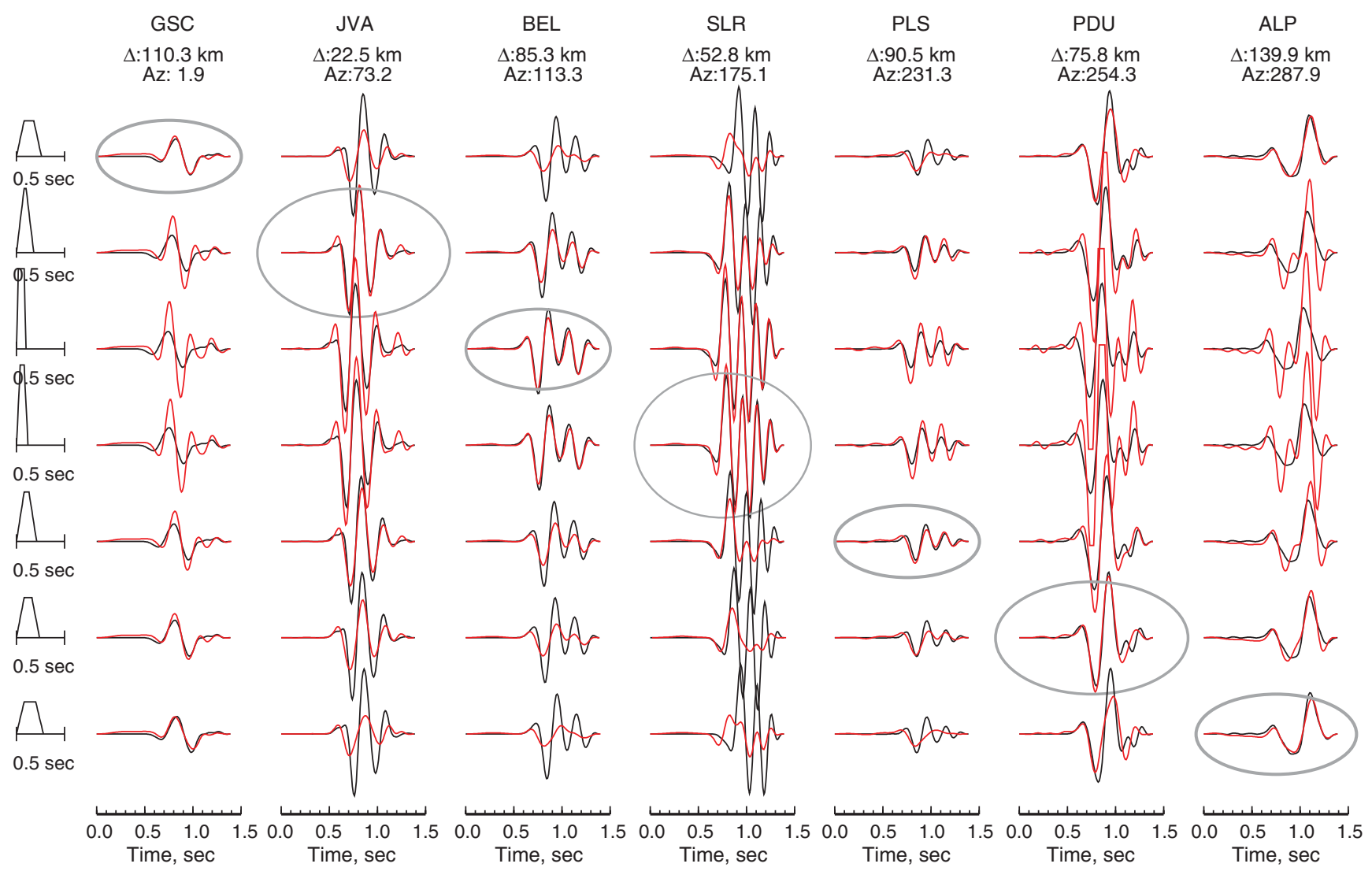

Figure 6. The selected waveform fits (vertical $P$ waves) between the records from event 13937492 (black) and the synthetics (red) constructed with EGFs from event 13937632. The relative source time functions (RSTFs) are given to the left. Plotted are the absolute amplitudes, except that scaling factors of $1 / 4,1 / 2$, and 2 have been applied to the stations JVA, PDU, and PLS, respectively, for the display purpose. The obtained best RSTFs for the stations are circled. Note the apparent azimuthal pattern of the RSTFs.

source was too complicated to be modeled with trapezoids. More details regarding the source complexity can be found in Tan (2006). Except for the three events where we could not obtain enough measurements, we were able to analyze the rupture directivity characteristics of nine events. In particular, the sources of the three disqualified events are found to contain significant short-scale heterogeneities, which causes the failure of the simple source model assumption; for example, event 13936076 appears as a doublet (Fig. 9). Besides event 13937492, we find six other events, five unilateral and one bilateral, exhibiting robust rupture directivity features (Fig. 10). The detailed results of these events will be briefly discussed here (Figs. 11-16).

Event $13935996\left(M_{\mathrm{w}} \sim 4.0\right)$ occurred about two minutes after the main event. It is located on the mainshock fault plane, at a slightly deeper depth than event 13937492 (Fig. 10). Our result (Fig. 11) confirms that the rupture is indeed on the northwest-southeast striking fault plane, however, it propagates toward the northwest, in the nearly opposite direction as event 13937492. Although there is some uncertainty, the observed azimuthal variation of $\tau_{c}$ is apparently smaller than that of event 13937492. As a result, the estimated fault length is shorter and the rupture speed is slower.
Event $13936596\left(M_{\mathrm{w}} \sim 3.7\right)$ occurred off the northwestsoutheast trending mainshock fault (Fig. 10). The results in Figure 12 from $P$ and $S$ waves consistently indicate that the rupture propagates toward the southwest on the northeastsouthwest striking fault plane. However, there is a fairly large discrepancy between the estimates of $f l$ and $V_{r}$ from $P$ and $S$ waves. By examining the waveform comparisons as those displayed in Figures 6 and 7, we notice that the $S$ waves contain much greater complexities than the $P$ waves, which has caused generally larger uncertainties in the $\tau_{c}$ estimates from $S$ waves. Therefore, we will give the $P$-wave result more credit.

Event 13936236 (Fig. 13) and event 13937600 (Fig. 14) are two events of similar magnitudes $\left(M_{\mathrm{w}} \sim 3.4\right)$ in the south end of the cluster, where the seismicity becomes more diffusive. Although they both have ruptures on the northwestsoutheast trending fault plane, the azimuthal variations of $\tau_{c}$ display nearly flipped-over patterns, suggesting rupture propagation in the opposite directions. In particular, the rupture of event 13936236 propagates toward the northwest, whereas event 13937600 propagates toward the southeast. Note the nice agreement between the $P$ - and $S$-wave results for both events.

Event 13936812 is a pure thrust event with east-west striking focal planes. Our analysis of the measured $\tau_{c} \mathrm{~s}$ with 


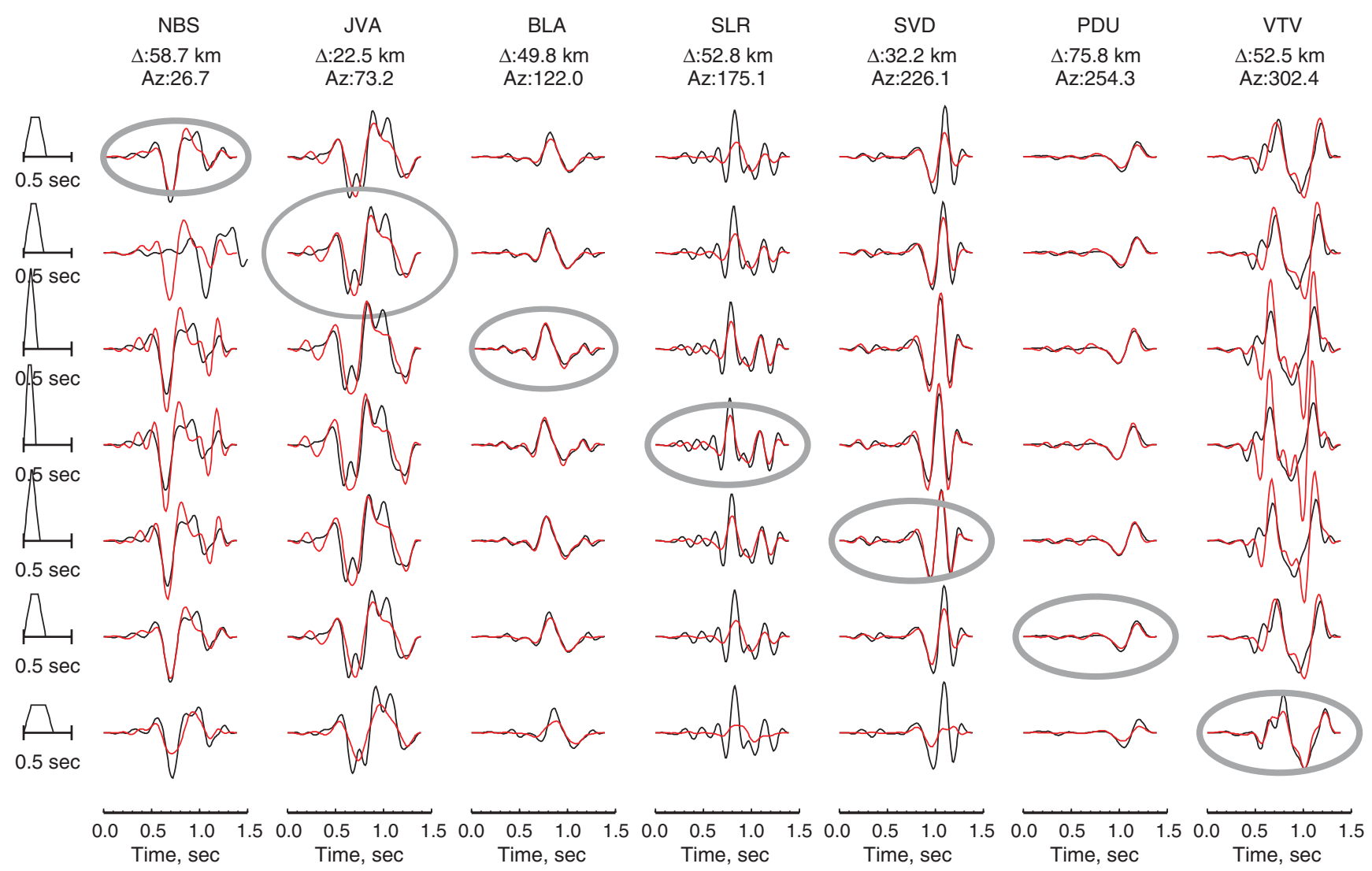

Figure 7. The selected waveform fits ( $S H$ waves) between the records from event 13937492 (black) and the synthetics (red) constructed with EGFs from event 13937632. Details are the same as in Figure 6.

(a)

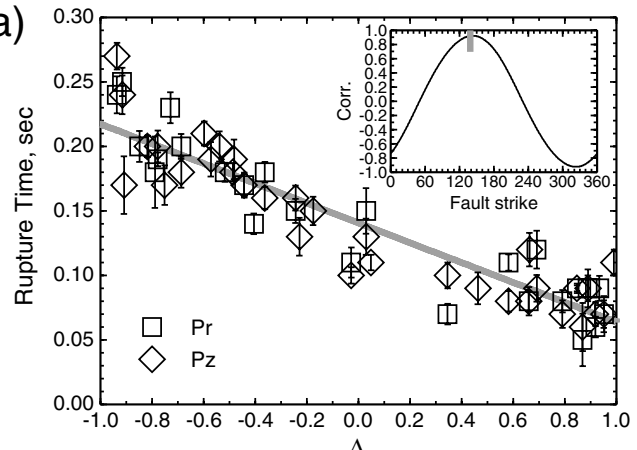

(c)

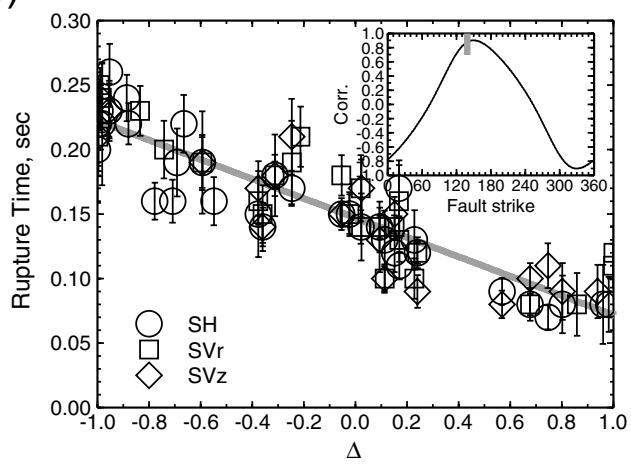

(b)

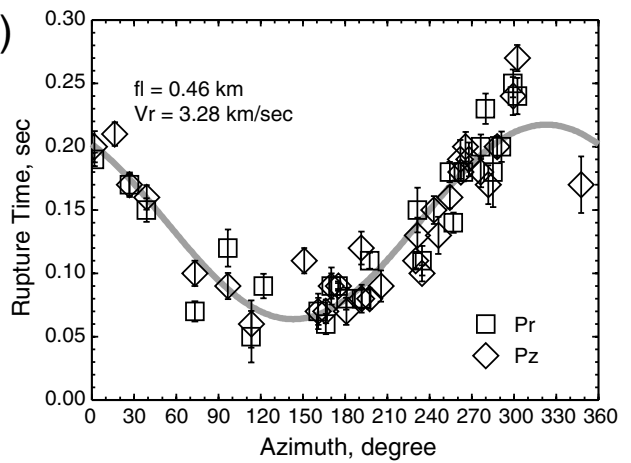

(d)

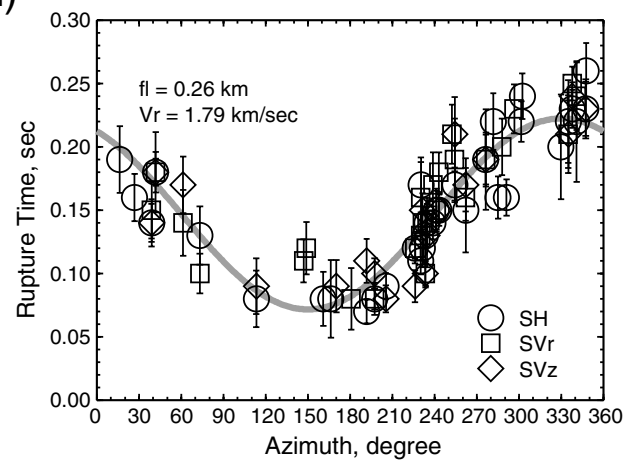

Figure 8. The result of rupture directivity for event 13937492 given a rise time $\tau_{r}$ of 0.02 sec. Details are the same as in Figure 5 . 


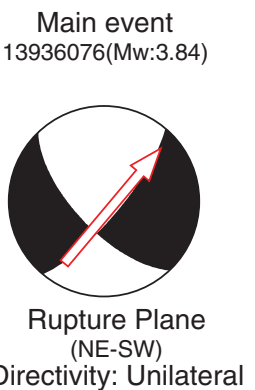

Directivity: Unilateral
EGF event

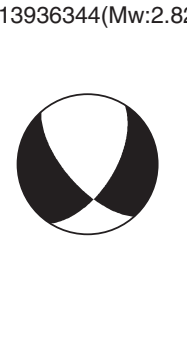

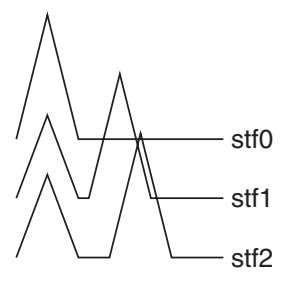

$\begin{array}{lllll}0.0 & 0.1 & 0.2 & 0.3 & 0.4\end{array}$

Time, sec
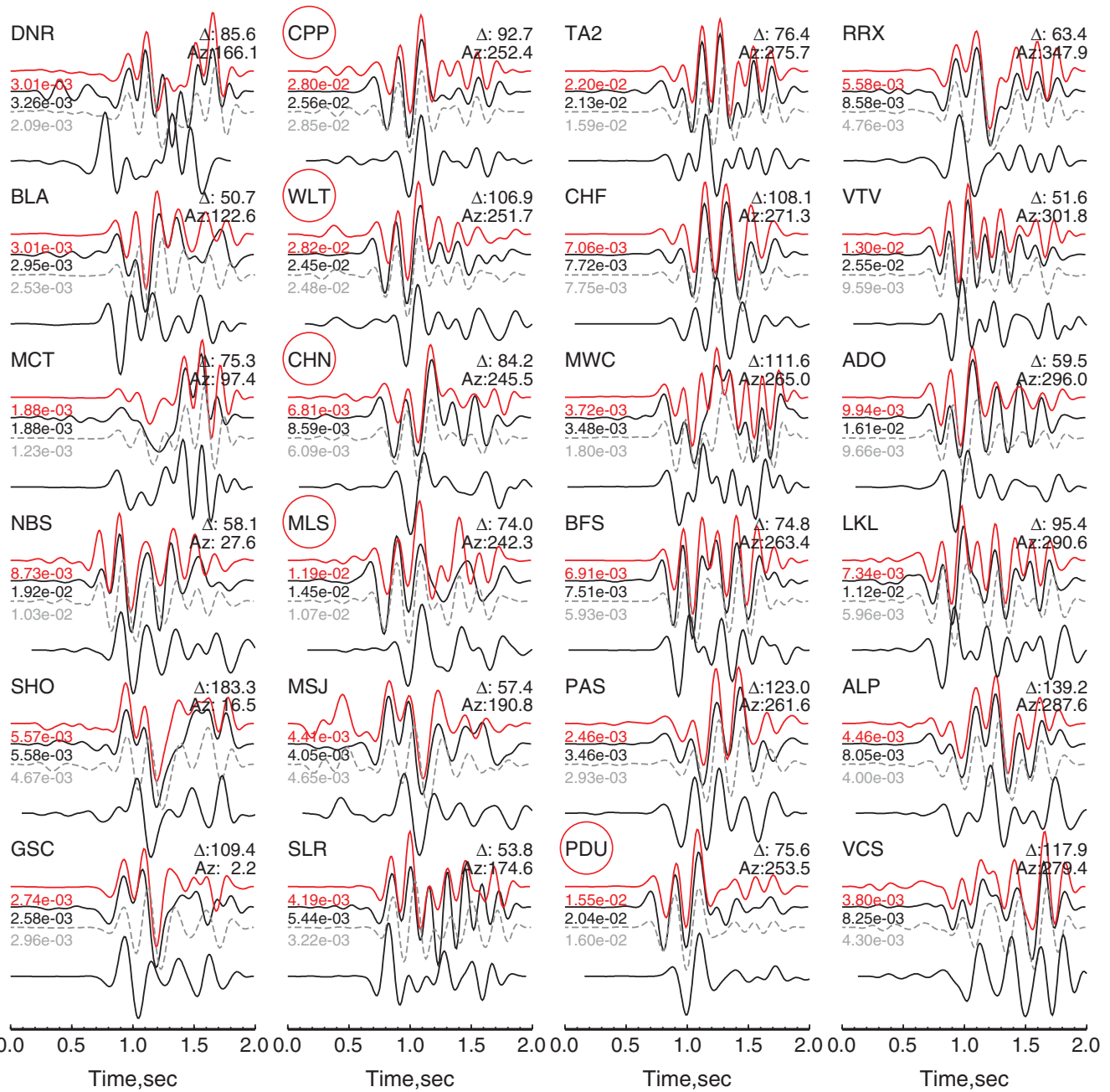

Figure 9. The waveform comparison between the records from event 13936076 and the associated EGF event 13936344. The four traces for each station, from top to bottom, are the EGF convolved with source time function stf1, the record from event 13936076, the EGF convolved with stf2, and the EGF convolved with the single pulse source time function stf0, respectively. Note the double-pulse source time function stf1 applies well to most stations. However, the few stations (circled) that are located along a certain azimuth $\sim 245^{\circ}$ require larger separations between the subevents, which might suggest that the rupture of event 13936076 propagates toward the northeast.

equation (7) revealed strong horizontal rupture directivity of the event as displayed in Figure 15a-e. The $P$ - and $S$-wave results consistently indicate that the rupture propagates toward the west, but unfortunately, the resolved rupture direction alone cannot tell the real fault plane from the auxiliary one, because both have a similar strike. The shallow dip of the fault plane, however, provides an opportunity to investigate possible vertical directivity (see equation 6). Figure 15 displays the linear correlation coefficients between $\tau_{c}$ and $\Delta^{\prime} \quad\left[\Delta^{\prime}=\cos (\varphi-\phi) \cos (\lambda)-\sin (\varphi-\phi) \sin (\lambda) \cos (\delta)\right]$ versus $\lambda$ from $P$ (Fig. 15f) and $S$ (Fig. 15g) waves, where the fault strike $\phi=270^{\circ}$ and $\operatorname{dip} \delta=45^{\circ}$ have been set. (Note 


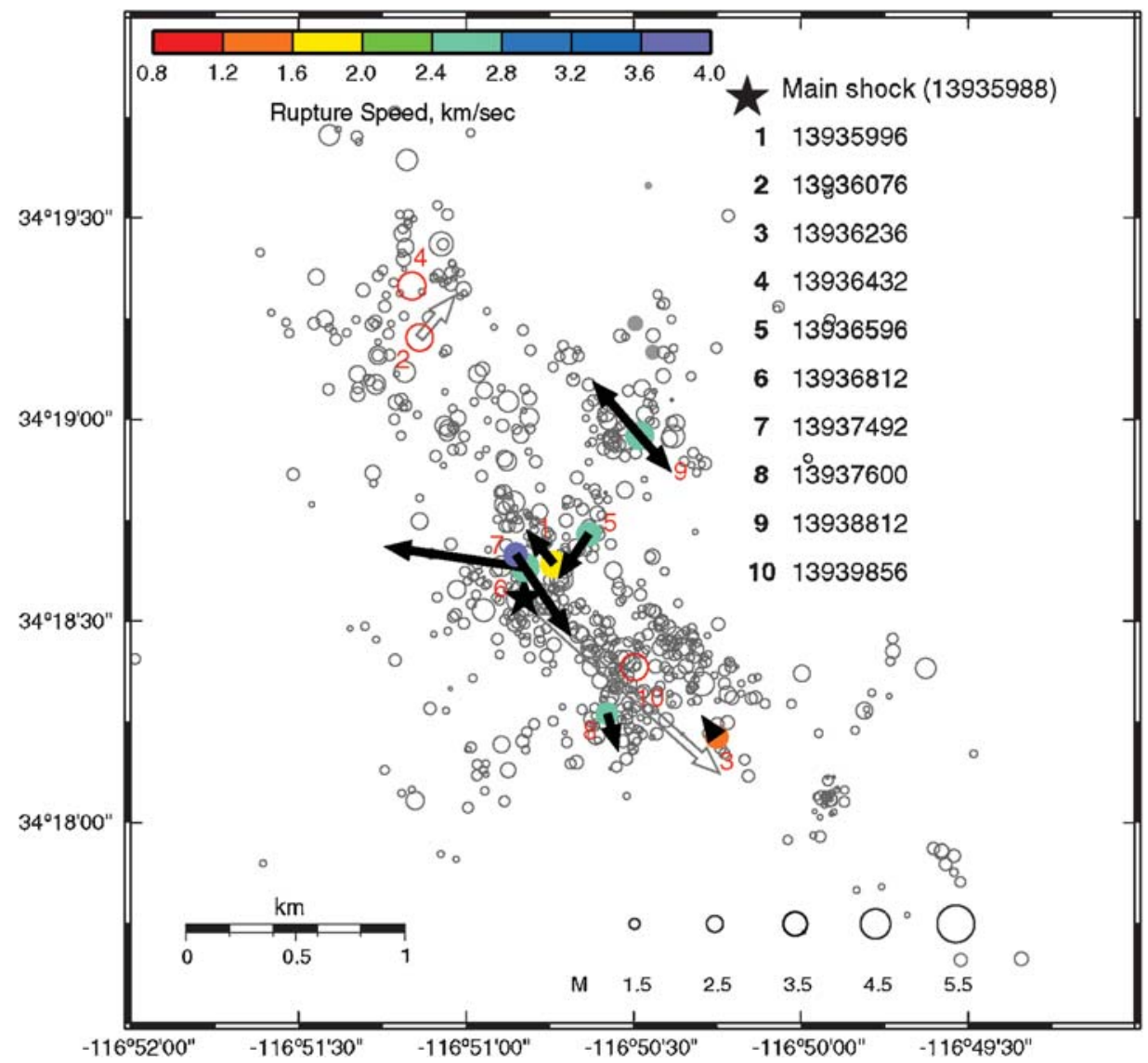

Figure 10. The studied events, ordered and labeled with their occurrence in time, are displayed together with the relocated seismicity from Chi and Hauksson (2006). In particular, those with robust rupture directivity as listed in Table 1 are color-coded with rupture speed. The arrows point to the rupture propagation directions with their lengths proportional to the fault lengths. The open arrows indicate the speculated rupture propagation for the mainshock, and the doublet event 13936076.

(a)

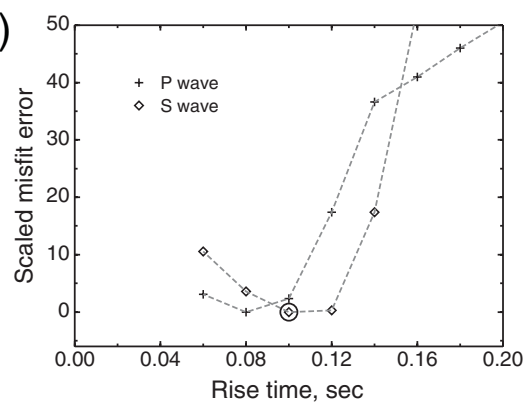

(b)

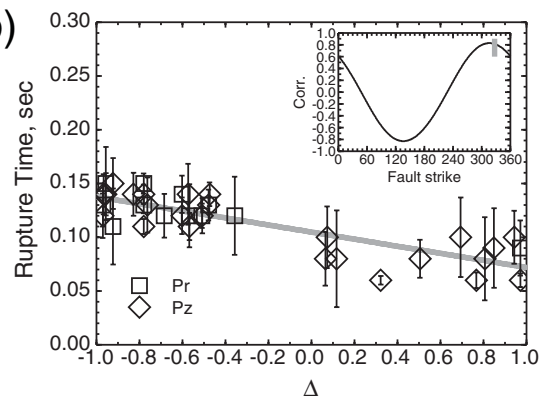

Main event 13935996 (Mw:4.0)

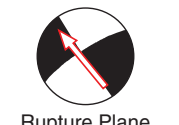

Rupture Plane

Directivity: Unilateral

EGF event

13936152 (Mw:3.0)

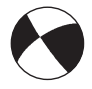

(d)

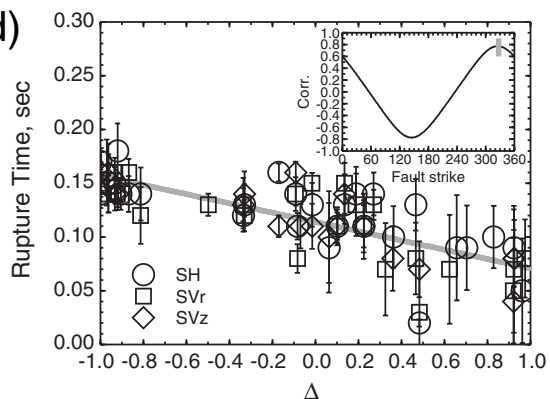

(c)

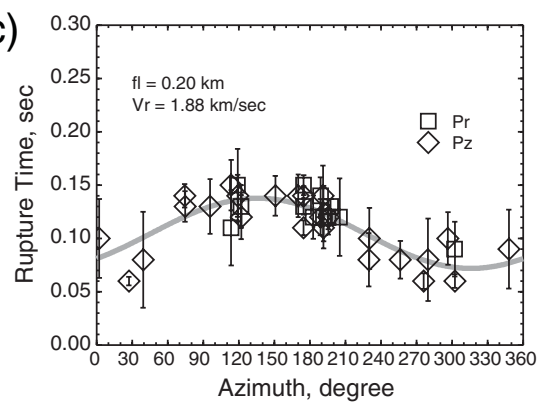

(e)

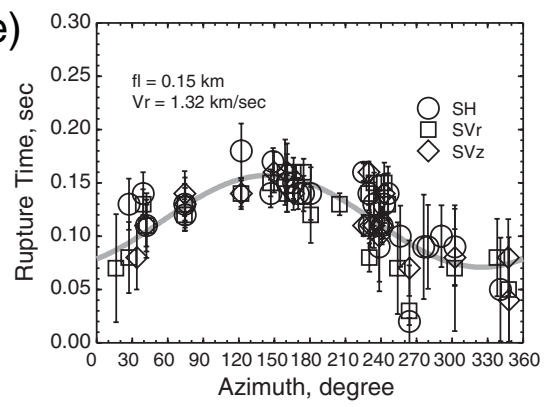

Figure 11. Rupture directivity result for Event 13935996. Details are the same as in Figure 5. 
(a)

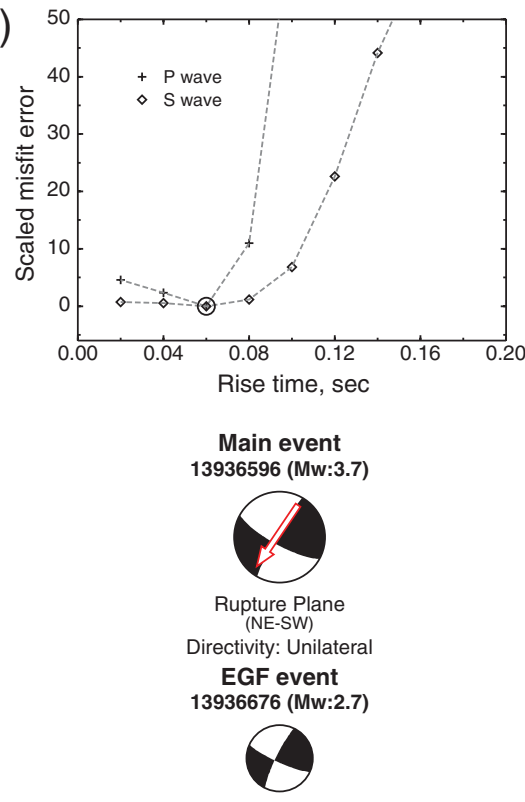

(b)

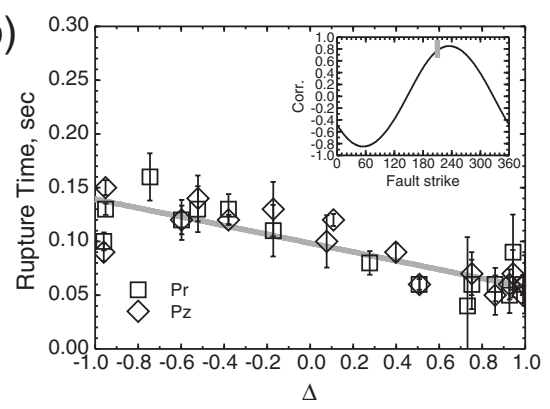

(d)

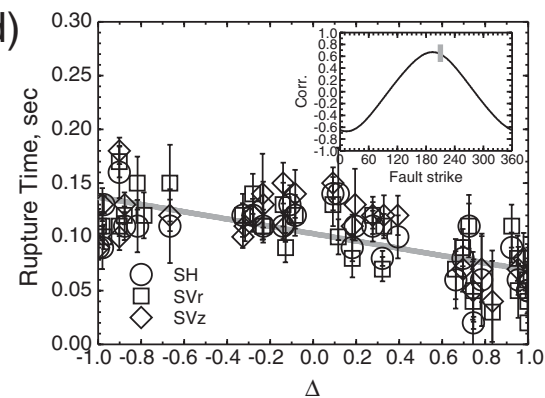

(c)

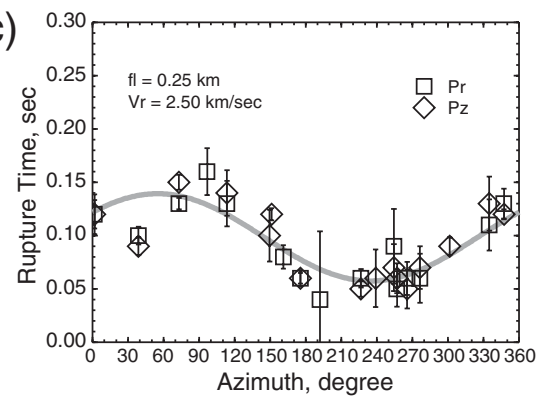

(e)

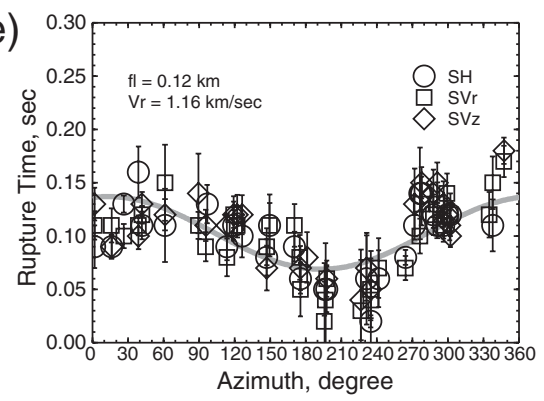

Figure 12. Rupture directivity result for Event 13936596. Details are the same as in Figure 5.

that both focal planes from the focal mechanism solution have a similar dip of $\sim 45^{\circ}$.) The well-resolved peak at $\lambda \sim 0^{\circ}$ clearly suggests fairly weak vertical rupture directivity.

Event 13938812 occurred the farthest from the mainshock fault plane among our studied events (Fig. 10). Although the measured $\tau_{c}$ s from the $P$ and $S$ waves display similar azimuthal trends, the variations in the $\tau_{c}$ s from the $S$ waves are much larger, which suggests that the rupture directivity has a bigger effect on $S$ waves. In particular, because the azimuthal variation of the $\tau_{c}$ s from the $P$ wave is almost below their own uncertainties, we will focus on interpreting the $S$-wave result. Our analysis assuming a unilateral rupture using equation (7) (Fig. 16b-e) roughly explains the observed azimuthal trend of $\tau_{c}$, but leaves a lot of details poorly fit. Besides, the resolved rupture direction differs from the strike of either fault plane from the focal mechanism solution by almost $\sim 45^{\circ}$. However, by using a bilateral rupture model, where the $\tau_{c} \mathrm{~s}$ are described as

$$
\tau_{c}=\max \left[\tau_{c}^{(1)}, \tau_{c}^{(2)}\right]
$$

where (a)
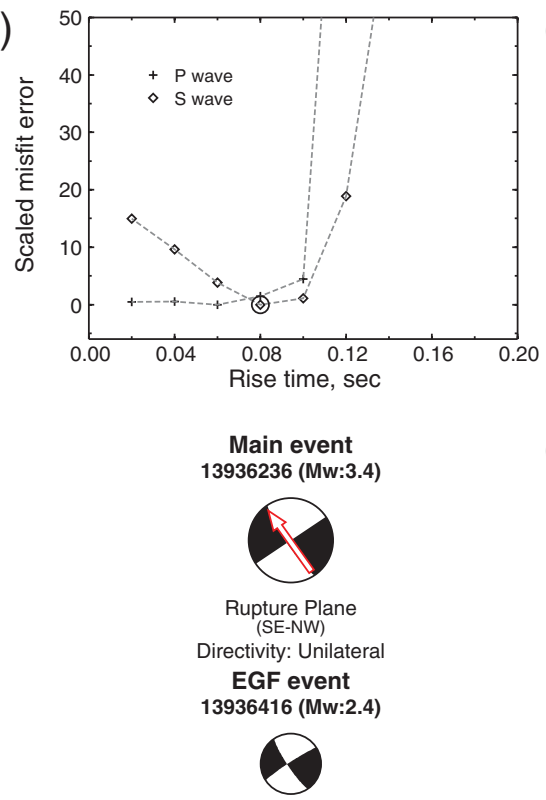

(b)

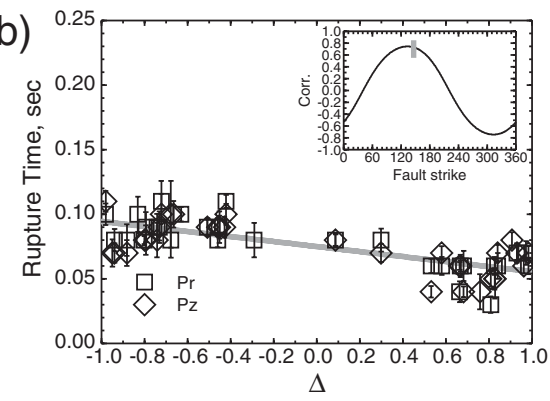

(d)

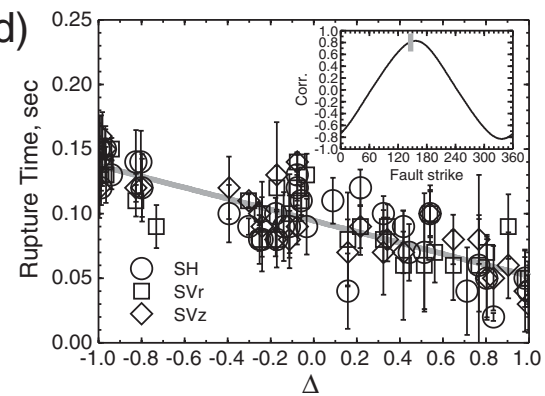

(c)

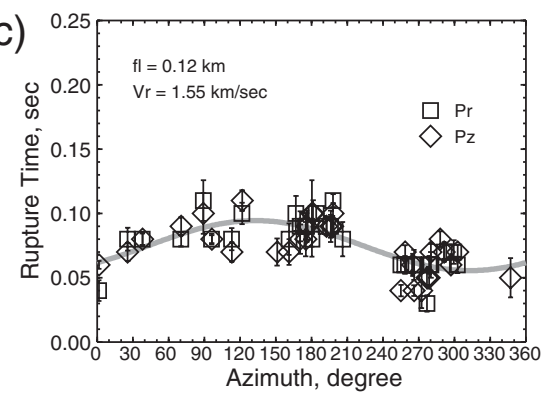

(e)

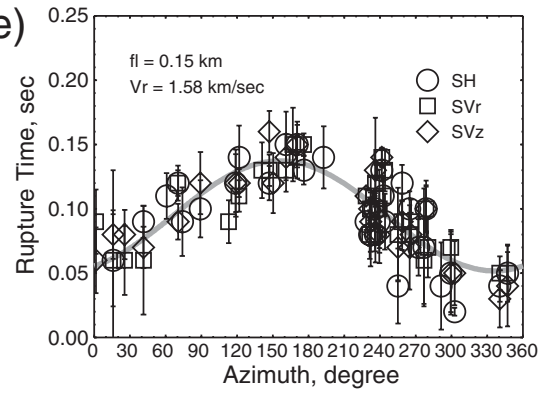

Figure 13. Rupture directivity result for Event 13936236. Details are the same as in Figure 5. 
(a)

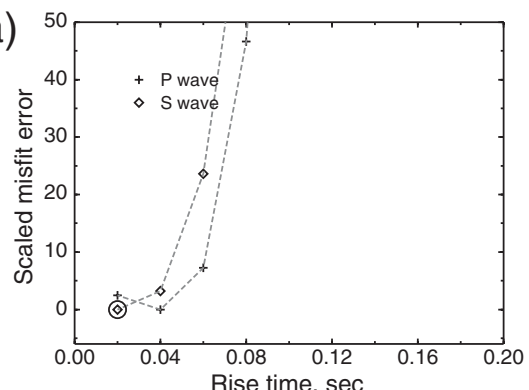

Main event

13937600 (Mw:3.4)

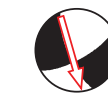

Rupture Plane (NW-SE)

Directivity: Unilateral

EGF event

13937644 (Mw:2.4)

e (b)

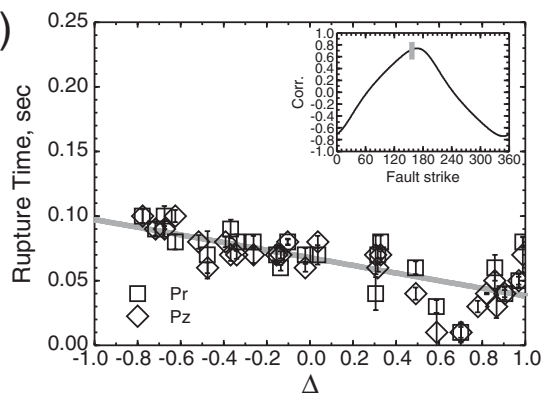

(d)

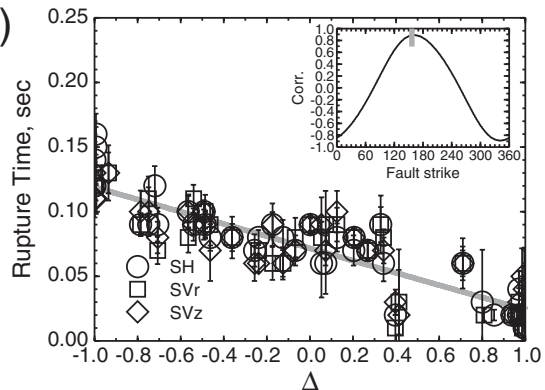

(c)

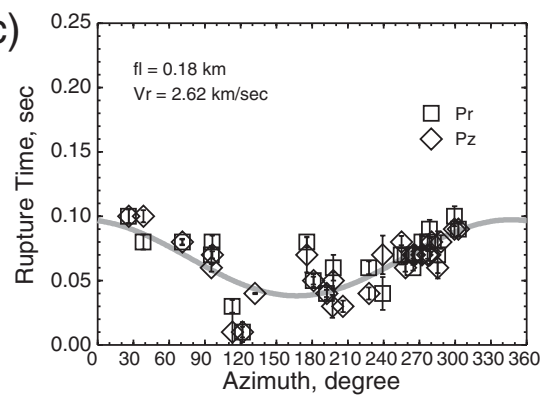

(e)

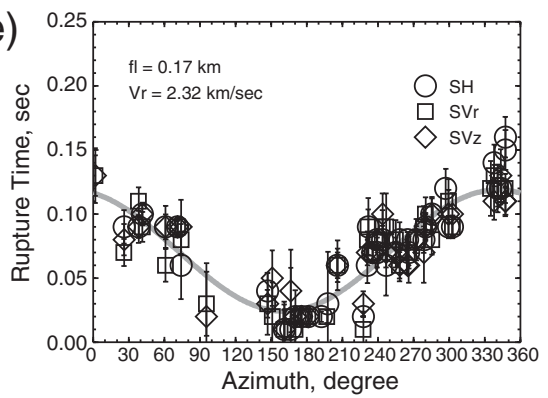

Figure 14. Rupture directivity result for Event 13937600 . Details are the same as in Figure 5 .

(a)

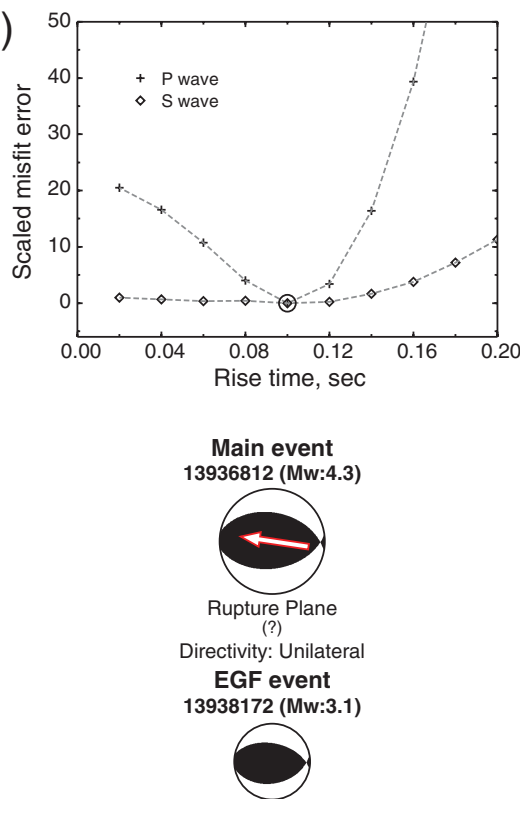

(b)

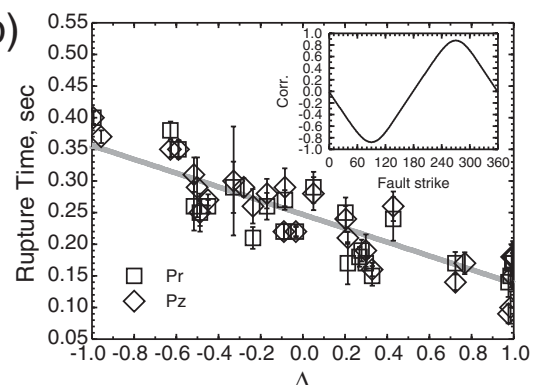

(d)

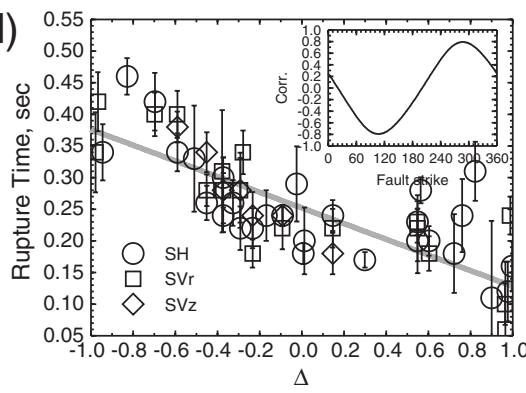

(f)

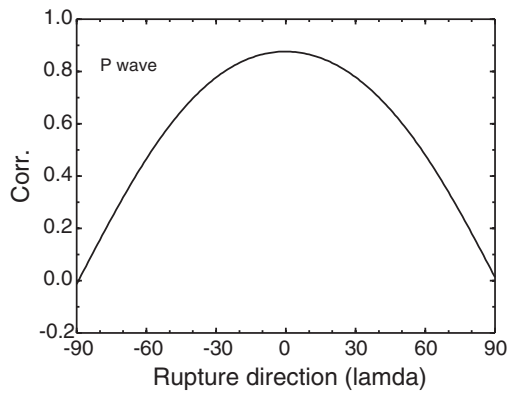

(c)

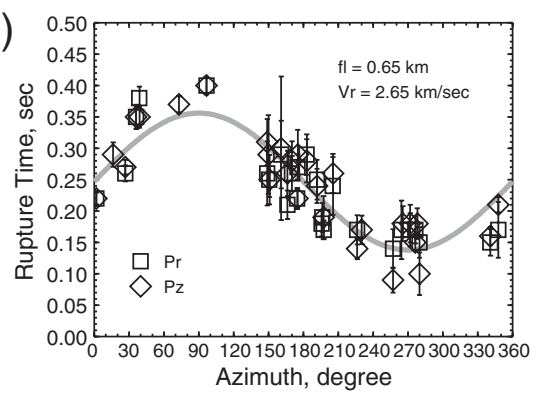

(e)

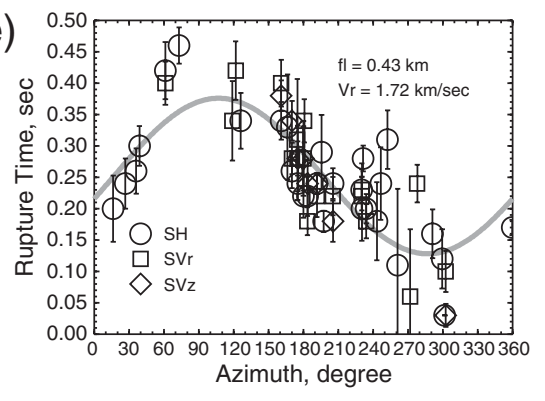

(g)

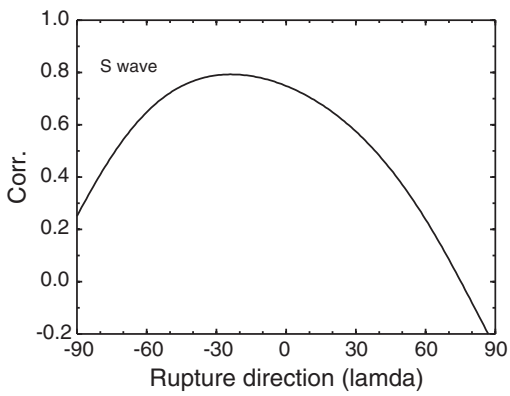

Figure 15. Rupture directivity result for Event 13936812. See the caption of Figure 5 for the details of (a)-(e). (f),(g) Graphs display the linear correlation coefficients between $\tau_{c}$ and $\Delta^{\prime}$ versus $\lambda$ from $P$ and $S$ waves. Note the peaks near $\lambda \sim 0$. 
(a)

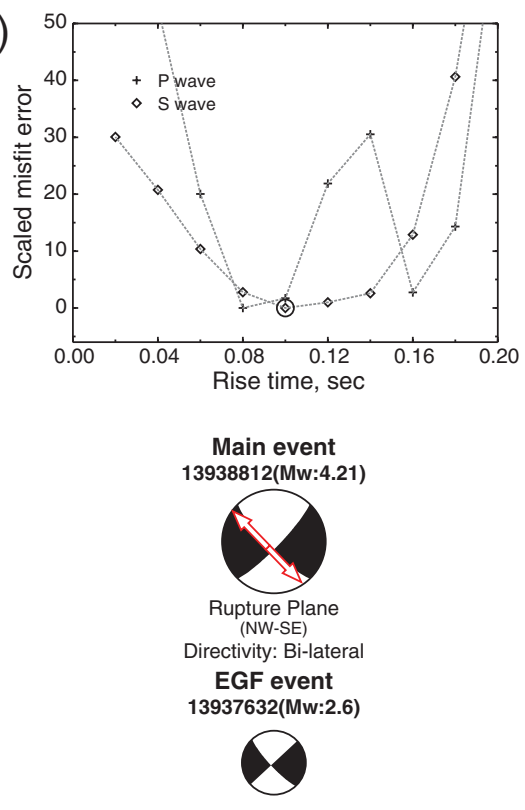

(b)

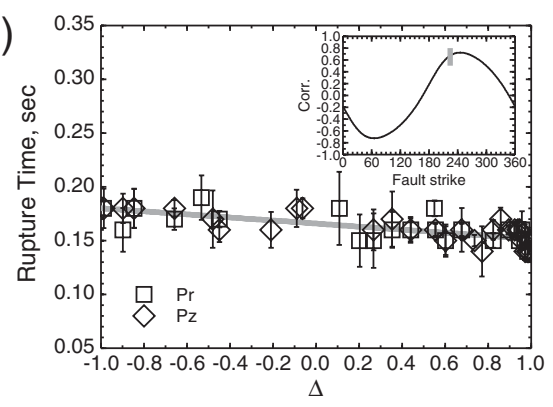

(d)

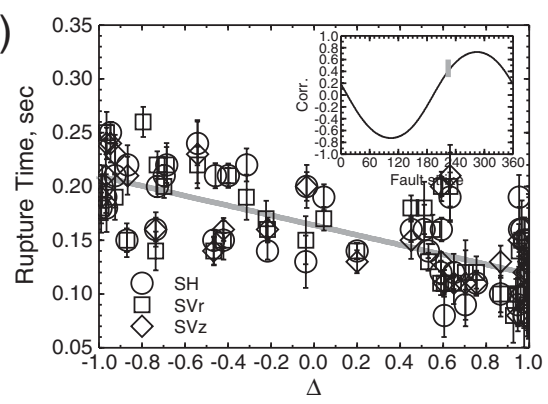

(f)

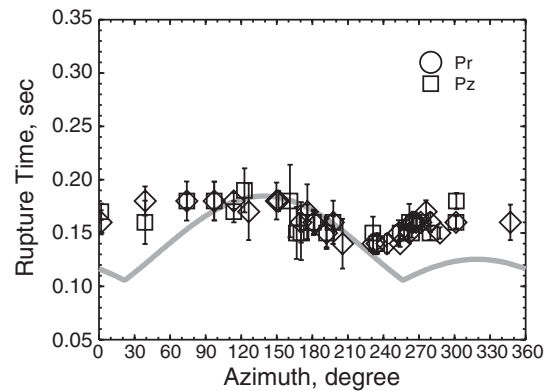

(c)

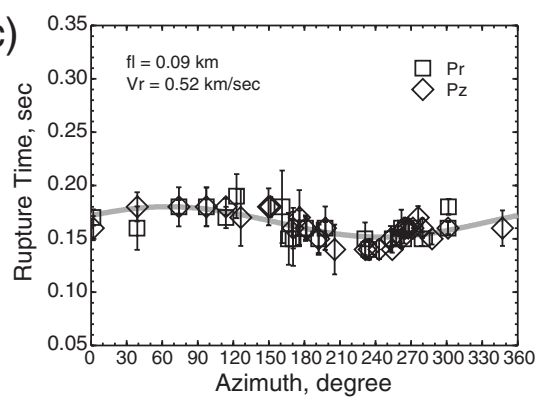

(e)

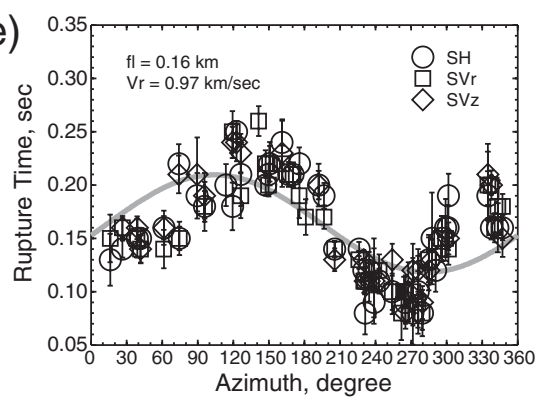

(g)

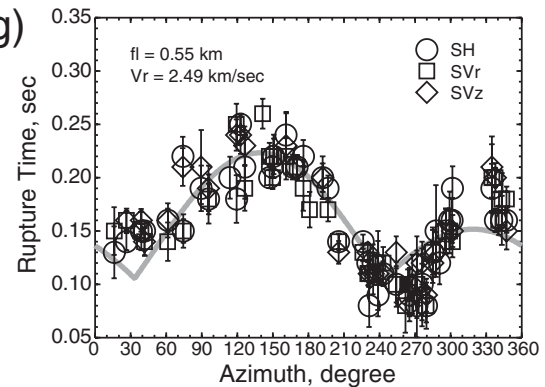

Figure 16. Rupture directivity result for Event 13938812. See the caption of Figure 5 for the details of (a)-(e). (f),(g) Graphs display the fitting of a bilateral rupture to the variations of $\tau_{c}$ versus azimuth. In particular, the source parameters determined from $S$ wave are used for $P$ wave.

(a)

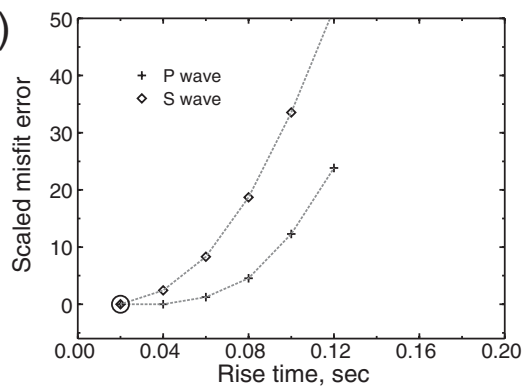

Main event 13939856 (Mw:3.8)

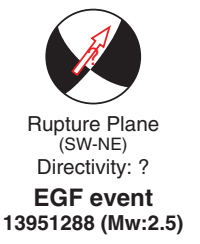

(b)

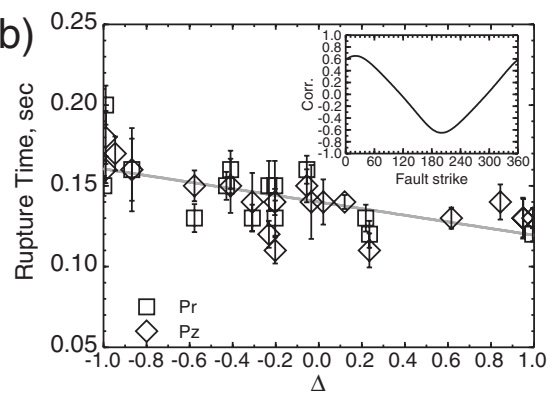

(d)

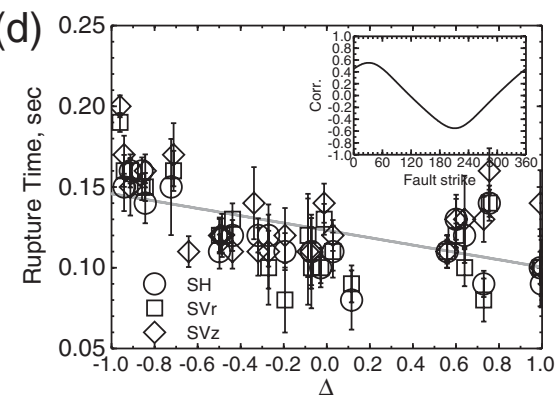

(c)

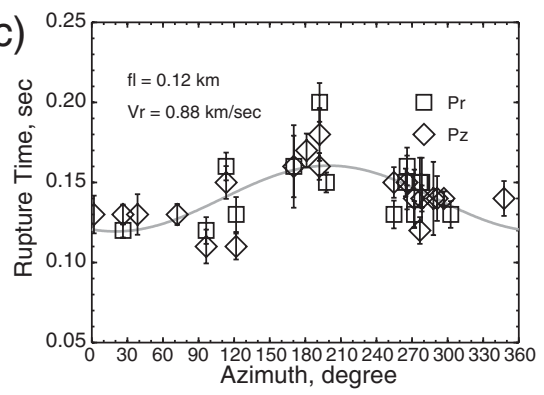

(e)

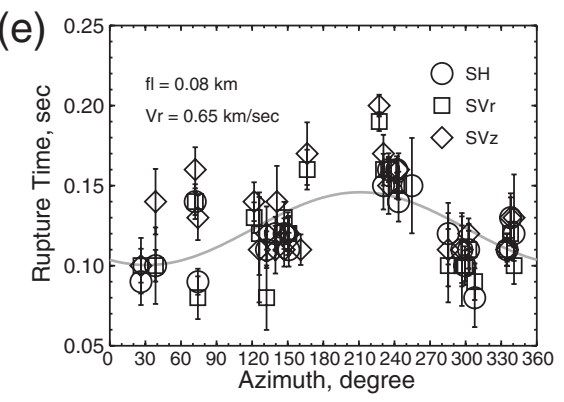

Figure 17. Rupture directivity result for Event 13939856. 
(a)

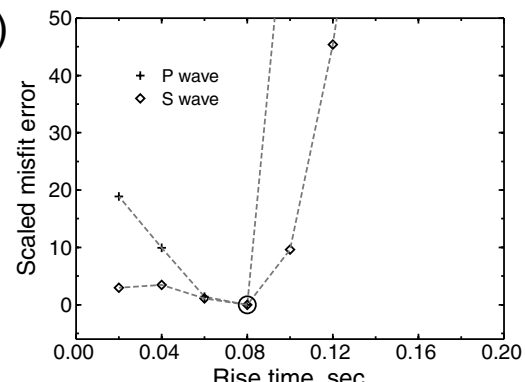

Main event 13936432(Mw:3.79)

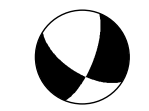

Rupture Plane ?

EGF event 13937200(Mw:2.6) $Q$ (b)

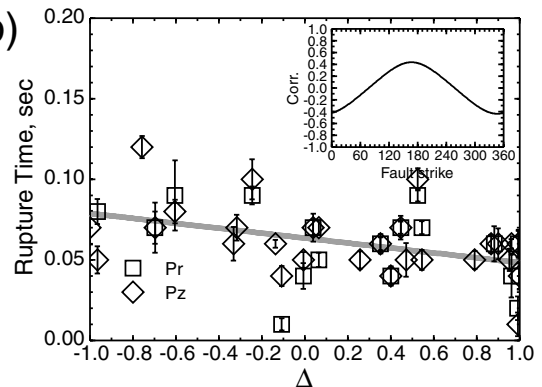

(d)

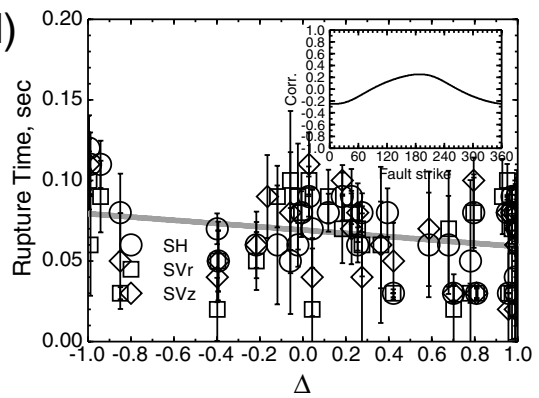

(C)

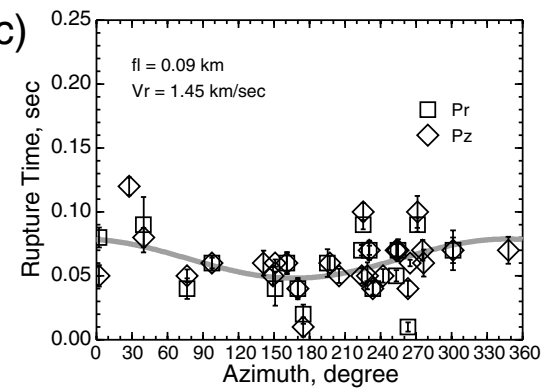

(e)

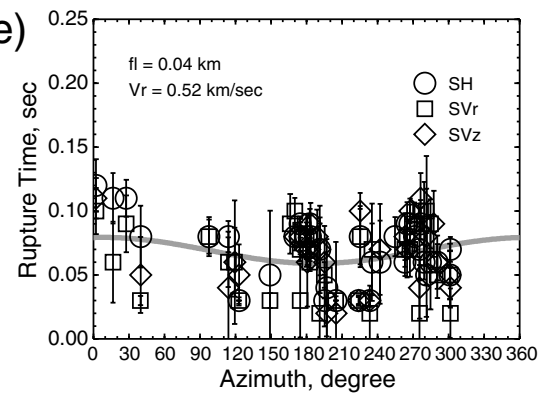

Figure 18. Rupture directivity result for Event 13936432.

$$
\begin{gathered}
\tau_{c}^{(1)}=\mathrm{Ra} \cdot \frac{f l}{V_{r}}\left\{1-\frac{V_{r}}{V_{P, S}}[\cos (\varphi-\phi) \cos (\lambda)]\right\}, \\
\tau_{c}^{(2)}=(1-\mathrm{Ra}) \cdot \frac{f l}{V_{r}}\left\{1-\frac{V_{r}}{V_{P, S}}[\cos (\varphi-\phi) \cos (-\lambda)\},\right.
\end{gathered}
$$

we can significantly improve the fitting for the measured $\tau_{c}$ (Fig. 16g). In addition, the inferred rupture direction agrees very well with the strike of the northwest-southeast fault plane. Ra and $1-\mathrm{Ra}$ introduced in equations (9) and (10) represent the fractions of the total fault length for the two ruptures that propagate in opposite directions. A Ra value of $\sim 0.4$ that we obtain in this case suggests that the rupture initiates near the center of the fault and then propagates toward two ends. We would like to emphasize that we only apply the bilateral analysis on the $\tau_{c}$ s from the $S$ waves, but the resolved source parameters can also roughly fit those from the $P$ waves (Fig. 16f).

In contrast to the events previously discussed, Figures 17 and 18 display a different scenario for events 13939856 and 13936432, where there is no clear azimuthal trend of the measured $\tau_{c}$ s. In particular, relatively low linear correlation coefficients $(<80)$ between $\tau_{c}$ and $\Delta$ for both $P$ and $S$ waves are observed. Besides, it is difficult to associate the resolved $\phi$ value with either fault plane of the focal mechanism solution due to their large discrepancy. Particularly for event 13936432 (Fig. 18), the $\tau_{c}$ estimates better approximate a constant rather than varying with azimuth. Note how well a single RSTF works for stations at all azimuths (Fig. 19). The lack of apparent rupture directivity might suggest small fault area, hence high stress drop for the event.

\section{Discussions and Conclusions}

We summarize the results from the studied events in Table 1 and on top of the 2003 Big Bear seismicity in Figure 10. The events are labeled in the order of their occurrences. For those exhibiting robust rupture directivity characteristics, the arrows are plotted pointing to the rupture propagation directions and their lengths are proportional to the estimated $\mathrm{fls}$. In addition, these events are color coded with $V_{r}$. We have simply chosen the $P$-wave results for Figure 10 of all the events, except for event 13938812, because the $S$-wave results are generally comparable with those from the $P$ waves, but might be less reliable due to the bigger uncertainties. For event 13938812, the results from $S$ waves are used.

The first observation in Figure 10 is the diversity of rupture directivity and the complicated pattern within the compact fault zone. Although most of the studied events have similar focal mechanisms (Fig. 1) and the relocated seismicity highlights the northwest-southeast trending of the fault system, crossover faults are clearly revealed from our results. In addition, the direction of rupture can be completely opposite, even when the two events are located on the same fault plane (e.g., events 1 and 7 in Fig. 10). Whether material contrast can predict earthquake rupture propagation direction has been in hot debate (e.g., Harris and Day, 2005; Ben-Zion, 2006; Harris and Day, 2006). However, to engage the resolved rupture directivity patterns with earthquake dynamics or the local geology is out of the scope of this article because our emphasis is in determining and documenting the rupture characteristics of a well-recorded earthquake sequence. Therefore, the following discussion will be focused on the variability and differences of the resolved rupture attributes. 


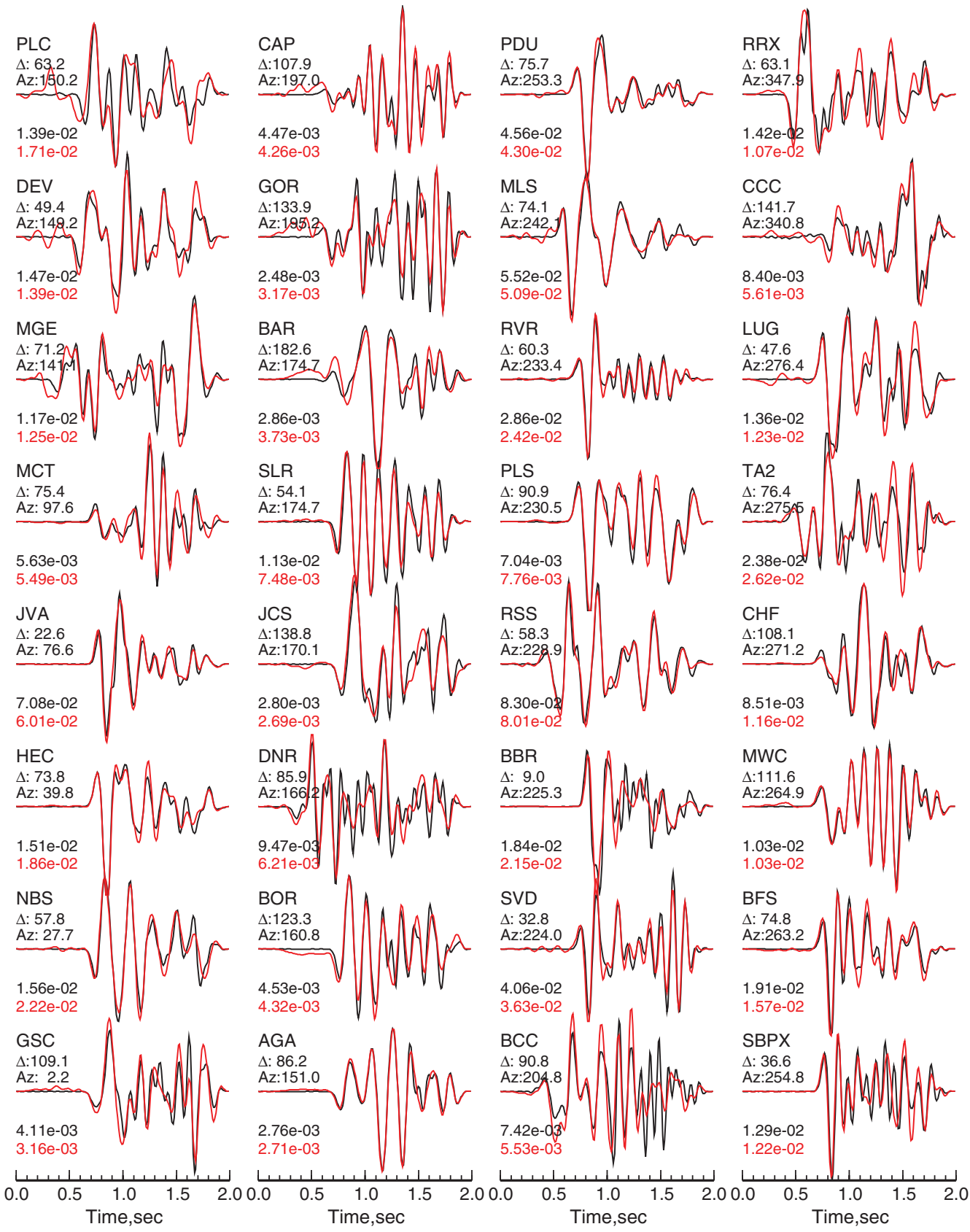

Figure 19. The records (vertical $P$ waves) from event 13936432 (black) are compared with the synthetics (red) constructed from the EGFs assuming a uniform triangular $(0.07-0.07 \mathrm{sec})$ source time function. A band-pass filter of $0.5-12 \mathrm{~Hz}$ has been applied. The amplitudes of the plotted traces are normalized by the maximum values given below the traces. Note the remarkable match between the shapes and amplitudes over the whole azimuthal range.

One such attribute is the estimated fault length $f l$. In particular, $f l$ exhibits large variations among the studied events (Table 1), however, with no dependence on seismic moment. Although the $\tau_{c}$ estimates from individual stations contain variable uncertainties, the $f l$ estimate derived from the slope of $\tau_{c}$ with respect to $\Delta$ (e.g., Fig. 5b) is robust, due to the full azimuthal coverage and data redundancy. Note that the $\tau_{c}$ s shuffle around besides an overall uplift when we assume a different rise time $\tau_{r}$ (Fig. 8). However, the slope of $\tau_{c}$ remains almost unchanged, suggesting its robustness.
Without a detailed velocity map, it is hard to quantify possible errors that the lateral variation of seismic velocity might have introduced into the $f l \mathrm{~s}$. But considering the compact size of the fault zone, besides, several events are actually located together (Fig. 10), we may expect little such effect. Another factor that can affect our $f l$ estimates is the source complexity of the EGF events. For example, if an EGF event itself has significant rupture directivity, the variations of its own source time function can add on to the $\tau_{c}$ variations observed for the target event, hence bias the $f l$ estimate. 
Table 1

Source Parameters of Seven Events with Rupture Directivity

\begin{tabular}{cccccccccr}
\hline & & & \multicolumn{3}{c}{ Estimates from $P$ Wave } & & \multicolumn{3}{c}{ Estimates from $S$ Wave } \\
\cline { 5 - 7 } \cline { 7 - 8 } Event & $M_{\mathrm{w}}$ & $\tau_{r}(\mathrm{sec})$ & $f l(\mathrm{~km})$ & $V_{r}(\mathrm{~km} / \mathrm{sec})$ & $\Delta \sigma(\mathrm{Mpa})$ & & $f l(\mathrm{~km})$ & $V_{r}(\mathrm{~km} / \mathrm{sec})$ & $\Delta \sigma(\mathrm{Mpa})$ \\
\hline 13937600 & 3.35 & 0.02 & 0.18 & 2.62 & 14.6 & & 0.17 & 2.32 & 17.3 \\
13936236 & 3.40 & 0.08 & 0.12 & 1.55 & 58.4 & & 0.15 & 1.58 & 29.9 \\
13937492 & 3.51 & 0.08 & 0.45 & 3.62 & 1.6 & & 0.36 & 2.94 & 3.2 \\
13936596 & 3.69 & 0.06 & 0.25 & 2.50 & 17.6 & & 0.12 & 1.16 & 159.0 \\
13935996 & 3.97 & 0.10 & 0.20 & 1.88 & 90.3 & & 0.15 & 1.32 & 214.1 \\
13938812 & 4.21 & 0.10 & & & & & 0.55 & 2.49 & 10.0 \\
13936812 & 4.31 & 0.10 & 0.65 & 2.65 & 8.5 & & 0.43 & 1.72 & 29.4 \\
\hline
\end{tabular}

In fact, rupture directivity for small events with magnitude $M_{L}$ down to $\sim 2.4$ has been reported (e.g., Frankel et al., 1986; McGuire, 2004). Because we deliberately choose the closest events in terms of both location and mechanism for the EGFs, the selected EGF events are quite different. We do not attempt to assess the rupture complexity of each EGF event. However, we have done some cross-checks similar to those displayed in Figures 3 or 19 among the EGF events, and found no convincing differential rupture directivity between any two events, which suggests that the effect due to the complexity of the EGF events might not be important in our case.

If we assume that the fault width scales approximately as the fault length, which is a good assumption for small earthquakes, we can compute the static stress drop $\Delta \sigma$ for each event (see Table 1) using the equation, for example, from Lay and Wallace (1995):

$$
\Delta \sigma \sim \frac{2}{\pi} \frac{M_{0}}{f l^{3}}
$$

Note that because $\Delta \sigma$ is inversely proportional to the cube of $f l$, the variations observed in $f l$ have been greatly magnified in the calculated $\Delta \sigma$, which ranges from about 1 to $90 \mathrm{Mpa}$. Due to the different modeling assumptions and the large scatter in the estimated stress drops, comparing the absolute values of $\Delta \sigma$ in our result with those from the previous studies in the area (e.g., Jones and Helmberger, 1996; Shearer et al., 2006) is not that meaningful. Particularly, the results from most previous studies (e.g., Mori and Frankel, 1990;
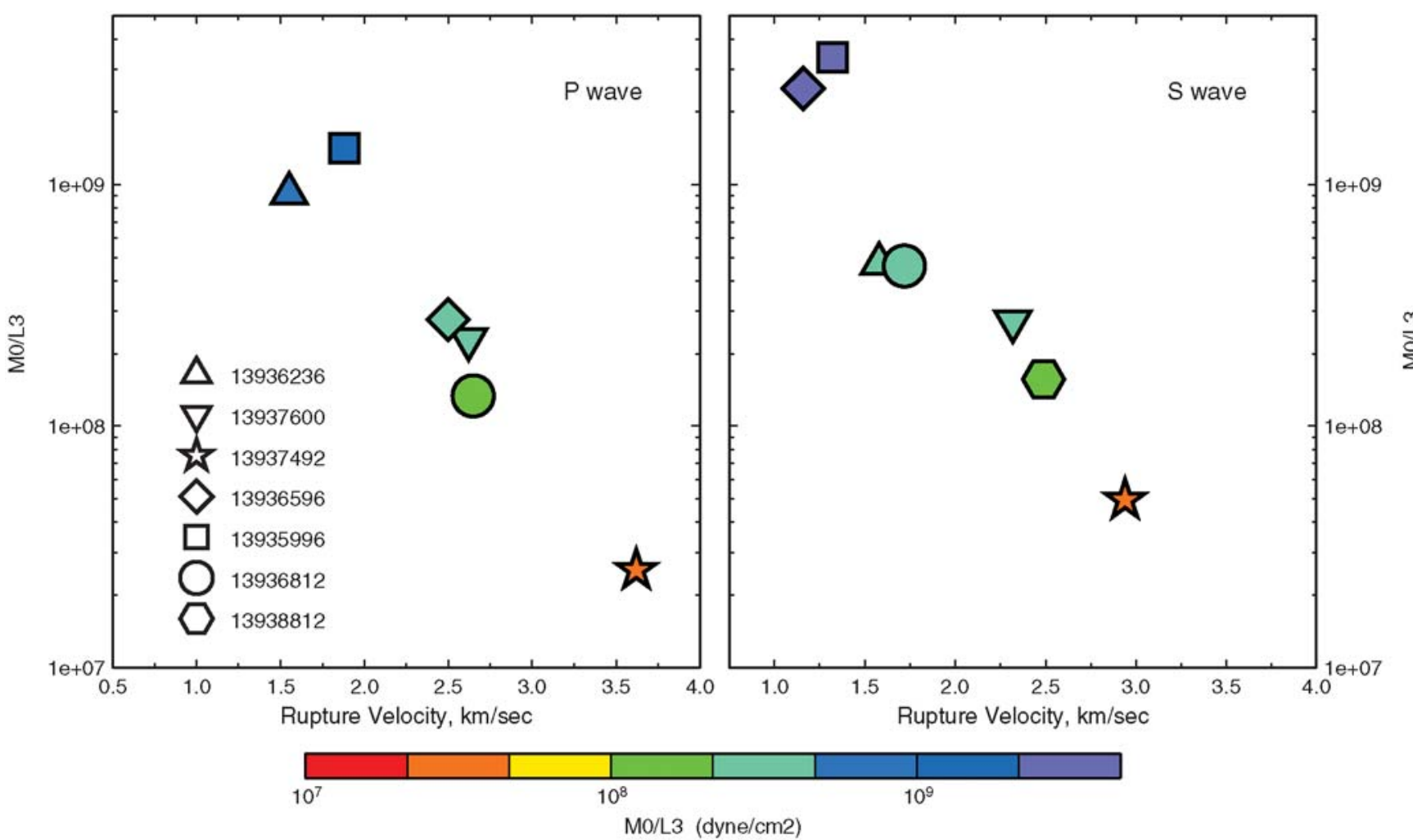

Figure 20. $\quad M_{0} / L^{3}$ versus $V_{r}$ from the studied events. The results from $P$ wave are displayed on the left, and the $S$-wave results are on the right. 
Hough and Dreger, 1995; Abercrombie, 1995; Jones and Helmberger, 1996, 1998; Hardebeck and Hauksson, 1997) based on source spectra analysis or $P$-wave pulse width are Brune-type stress drops (Brune, 1970) assuming a circular fault. A detailed review of these studies can be found in Shearer et al. (2006). As it might be predicted, for events with strong rupture directivity, ignoring the azimuthal variations of the source term can easily introduce significant errors into $\Delta \sigma$. Although the omitted term $\left(\frac{L}{W}\right)^{2}$ in equation (11), which represents the square of the fault aspect ratio, can change our stress drop estimates, it can hardly reconcile the large difference with a factor of nearly 100 between the high stress drop and low stress drop events. Therefore, we wish to emphasize the robustness of the large variations in our resolved stress drops, which suggests considerable stress/strength variations over hundreds of meters. Large variations of $\Delta \sigma$ of similar size have been noted in many studies (e.g., Kanamori et al., 1993; Hough and Dreger, 1995; Shearer et al., 2006; Allmann and Shearer, 2007).

Another result that is noteworthy in Figure 10 is the large variation of the estimated rupture speed $V_{r}$, which ranges from approximately $0.5 \beta$ to $\beta$. Although the rupture speed of $\sim 0.8 \beta-\beta$ has been observed and used as a rule of thumb in many studies (e.g., Frankel et al., 1986; Fletcher and Spudich, 1998; McGuire, 2004), faster or slower rupture speeds are being reported (e.g., Steidl et al., 1991; Bouchon et al., 2001; Ammon et al., 2005; Robinson et al., 2006; Liu and Shi, 2008). Compared with the $f l$ estimates, the $V_{r}$ values in our result might contain larger errors. Besides the trade-off between $\tau_{r}$ and $V_{r}$ that we have addressed in Figure 8, the finite source duration of the EGF events might have a similar effect. In particular, $V_{r}$ can be overestimated if $\frac{f l}{V_{r}}$ is underestimated due to the finite source duration of the EGF event. However, even given these uncertainties, the variations of $V_{r}$ still seem robust because the differential source duration of one event to another is fairly small among the EGF events. Of particular interest is the apparent correlation between our estimated $M_{0} / L^{3}$ and $V_{r}$ as displayed in Figure 20. Such inverse proportionality of $\Delta \sigma$ to $V_{r}$ is consistent with the scale dependent $\Delta \sigma V_{r}^{3}$ predicted by Kanamori and Rivera (2004), although with the limited data points, we are not able to examine the moment dependence of $\Delta \sigma V_{r}^{3}$. It appears in Figure 20 that events with low $\Delta \sigma$, likely on weak faults, tend to propagate at high $V_{r}$; whereas events with high $\Delta \sigma$, likely on strong faults, propagate at low $V_{r}$.

In summary, we have developed a forward modeling approach to retrieve rupture directivity of small events, which fully utilizes both the duration and amplitude information produced by rupture propagation. We applied the approach to the $2003 \mathrm{Big}$ Bear sequence and successfully resolved the rupture directivity characteristics of nine events. The rupture directions of these events reveal great complexity in the fault geometry at depth. The estimated static stress drops show large variations ranging from $\sim 1$ to $90 \mathrm{Mpa}$, with no dependence on seismic moment. However, $\Delta \sigma$ appears inversely correlated with rupture speed $\left(V_{r}\right)$. In particular, events with larger $\Delta \sigma$ tend to propagate at smaller $V_{r}$, whereas events with smaller $\Delta \sigma$ propagate faster.

\section{Data and Resources}

Seismic data used in this article were retrieved with the Seismic Transfer Program from Southern California Earthquake Data Center. Plots were made using the Generic Mapping Tools version 4.2.0.

\section{Acknowledgments}

The authors are grateful to Hiroo Kanamori for helpful discussions. Lupei Zhu and Chen Ji reviewed the early draft and provided useful suggestions. Two anonymous reviewers provided helpful comments to improve the article. This work was supported by USGS NEHRP grant G09AP00082. California Institute of Technology Seismological Laboratory contribution 10037.

\section{References}

Aagaard, B., T. Brocher, D. Dolenc, D. Dreger, R. W. Graves, S. Harmsen, S. Hartzell, S. Larsen, K. McCandless, S. Nilsson, N. A. Petersson, A. Rodgers, Björn Sjögreen, and M. L. Zoback (2008). Groundmotion modeling of the 1906 San Francisco earthquake, part II: Ground-motion estimates for the 1906 earthquake and scenario events, Bull. Seismol. Soc. Am. 98, no. 2, 1012-1046.

Abercrombie, R. E. (1995). Earthquake source scaling relationships from -1 to $5 m_{l}$ using seismograms recorded at 2.5-km depth, J. Geophys. Res. 100, no. B12, 24,015-24,036.

Allmann, B. P., and P. M. Shearer (2007). Spatial and temporal stress drop variations in small earthquakes near Parkfield, J. Geophys. Res. 112, no. $112, \mathrm{~B} 04,305$.

Ammon, C. J., C. Ji, H-K Thio, D. Robinson, S. Ni, V. Hjorleifsdottir, H. Kanamori, T. Lay, S. Das, D. Helmberger, G. Ichinose, J. Polet, and D. Wald (2005). Rupture process of the 2004 Sumatra-Andaman earthquake, Science 308, no. 5725, 1133-1139.

Ammon, A. J., A. A. Velasco, and T. Lay (1993). Rapid estimation of rupture directivity-Application to the 1992 Landers $\left(M_{\mathrm{s}}=7.4\right)$ and Cape Mendocino $\left(M_{\mathrm{s}}=7.2\right)$, California earthquakes, Geophys. Res. Lett. 20, no. 2, 97-100.

Ben-Zion, Y. (2006). Comments on "Material contrast does not predict earthquake rupture propagation direction" by R. A. Harris and S. M. Day, Geophys. Res. Lett. 33, L13310, doi 10.1029/2005GL025, 652.

Boatwright, J. (2007). The persistence of directivity in small earthquakes, Bull. Seismol. Soc. Am. 97, no. 6, 1850-1861.

Bouchon, M., M. P. Bouin, H. Karabulut, M. N. Toksoz, M. Dietrich, and A. J. Rosakis (2001). How fast is rupture during an earthquake? New insights from the 1999 Turkey earthquakes, Geophys. Res. Lett. 28, no. $14,2723-2726$.

Brune, J. N. (1970). Tectonic stress and spectra of seismic shear waves from earthquakes, J. Geophys. Res. 75, 4997-5009.

Chi, W.-C., and E. Hauksson (2006). Fault-perpendicular aftershock clusters following the $2003 M_{\mathrm{w}}=5.0 \mathrm{Big}$ Bear, California, earthquake, Geophys. Res. Lett. 33, no. 7, doi 10.1029/2005GL025033

Courboulex, F., S. K. Singh, J. F. Pacheco, and C. J. Ammon (1997). The 1995 Colima-Jalisco, Mexico, earthquake $\left(M_{\mathrm{w}} 8\right)$ : A study of the rupture process, Geophys. Res. Lett. 24, no. 9, 1019-1022.

de Lorenzo, S., M. Filippucci, and E. Boschi (2008). An EGF technique to infer the rupture velocity history of a small magnitude earthquake, J. Geophys. Res. 113, B10314, doi 10.1029/2007JB005, 496.

Fletcher, J. B., and P. Spudich (1998). Rupture characteristic of the three $M \sim 4.7$ (1992-1994) Parkfield earthquakes, J. Geophys. Res. 103, no. B1, 835-854. 
Frankel, A., and H. Kanamori (1983). Determination of rupture duration and stress drop for earthquakes in southern California, Bull. Seismol. Soc. Am. 73, no. 6, 1527-1551.

Frankel, A., J. Fletcher, F. Vernon, L. Haar, J. Berger, T. Hanks, and J. Brune (1986). Rupture characteristics and tomographic source imaging of $M \sim 3$ earthquakes near Anza, southern California, J. Geophys. Res. 91, no. B12, 12,633-12,650.

Hardebeck, J. L., and E. Hauksson (1997). Static stress drop in the 1994 Northridge, California, aftershock sequence, Bull. Seismol. Soc. Am. 87, no. 6, 1495-1501.

Harris, R. A., and S. M. Day (2005). Material contrast does not predict earthquake rupture propagation direction, Geophys. Res. Lett. 32, L23301, doi 10.1029/2005GL023, 941.

Harris, R. A., and S. M. Day (2006). Reply to comment by Y. Ben-Zion on "Material contrast does not predict earthquake rupture propagation direction”, Geophys. Res. Lett. 33, L13311, doi 10.1029/2006GL026 811

Hartzell, S. H. (1978). Earthquake aftershocks as Green's functions, Geophys. Res. Lett. 5, no. 1, 1-4.

Haskell, N. A. (1964). Total energy and energy spectra density of elastic waves from propagating faults, Bull. Seismol. Soc. Am. 54, 1811-1841.

Hough, S. E., and D. S. Dreger (1995). Source parameters of the 23 April 1992 M 6.1 Joshua Tree, California, earthquake and its aftershocks: Empirical Green's function analysis of GEOS and TERRAscope data, Bull. Seismol. Soc. Am. 85, 1576-1590.

Ji, C., D. J. Wald, and D. V. Helmberger (2002). Source description of 1999 Hector Mine, California earthquake, Part I: Wavelet domain inversion and resolution analysis, Bull. Seismol. Soc. Am. 92, no. 4, 1192-1207.

Jones, L. E., and D. V. Helmberger (1996). Seismicity and stress-Drop in the eastern transverse ranges, southern California, Geophys. Res. Lett. 23, 233-236.

Jones, L. E., and D. V. Helmberger (1998). Earthquake source parameters and fault kinematics in the eastern California shear zone, Bull. Seismol. Soc. Am. 88, no. 6, 1337-1352.

Kanamori, H., and L. Rivera (2004). Static and dynamic scaling relations for earthquakes and their implications for rupture speed and stress drop, Bull. Seismol. Soc. Am. 94, no. 1, 314-319.

Kanamori, H., J. Mori, E. Hauksson, T. H. Heaton, L. K. Hutton, and L. Jones (1993). Determination of earthquake energy release and $M_{\mathrm{L}}$ using TERRAscope, Bull. Seismol. Soc. Am. 83, 330-346.

Konca, A. O., V. Hjorleifsdottir, T-R A. Song, J-P Avouac, D. V. Helmberger, C. Ji, K. Sieh, R. Briggs, and A. Meltzner (2007). Rupture kinematics of the $2005 M_{\mathrm{w}} 8.6$ Nias-Simeulue earthquake from the joint inversion of seismic and geodetic data, Bull. Seismol. Soc. Am. 97, no. 1, S307-S322.
Lanza, V., D. Spallarossa, M. Cattaneo, D. Bindi, and P. Augliera (1999). Source parameters of small events using constrained deconvolution with empirical Green's functions, Geophys. J. Int. 137, 651-662.

Lay, T., and T. C. Wallace (1995). Modern Global Seismology, Academic Press, New York.

Liu, B.-Y., and B.-P. Shi (2008). Estimation of rupture speed for the 1995 $m_{l} 4.1$ Shacheng, Hebei, China, earthquake, Chinese Journal of Geophysics-Chinese Edition, 51, no. 6, 1797-1803.

McGuire, J. J. (2004). Estimating finite source properties of small earthquake ruptures, Bull. Seismol. Soc. Am. 94, no. 2, 377-393.

Mori, J. (1993). Fault plane determination for three small earthquakes along the San Jacinto fault, California: Search for cross faults, J. Geophys. Res. 98, no. B10, 17,711-17,722.

Mori, J., and A. Frankel (1990). Source parameters for small events associated with the 1986 North Palm Springs, Califorina, earthquake determined using empirical Green functions, Bull. Seismol. Soc. Am. 80, 278-295.

Robinson, D. P., C. Brough, and S. Das (2006). The $M_{\mathrm{w}}$ 7.8, 2001 Kunlunshan earthquake: Extreme rupture speed variability and effect of fault geometry, J. Geophys. Res. 111, no. B08303 doi 10.1029/ 2005JB004137.

Shearer, P. M., G. A. Prieto, and E. Hauksson (2006). Comprehensive analysis of earthquake source spectra in southern California, J. Geophys. Res. 111, no. B6, 303.

Steidl, J. H., R. J. Archuleta, and S. H. Hartzell (1991). Rupture history of the 1989 Loma-Prieta, California, earthquake, Bull. Seismol. Soc. Am. 81, no. 5, 1573-1602.

Tan, Y. (2006). Broadband waveform modeling over a dense seismic network, Ph.D. Thesis, California Institute of Technology, Pasadena, California.

Tan, Y., and D. Helmberger (2007). A new method for determining small earthquake source parameters using short-period $P$ waves, Bull. Seismol. Soc. Am. 97, no. 4, 1176-1195.

Venkataraman, A., J. Mori, H. Kanamori, and L. Zhu (2000). Fine structure of the rupture zone of the April 26 and 27, 1997, Northridge aftershocks, J. Geophys. Res. 105, no. B8, 19,085-19,093.

Seismological Laboratory

252-21

California Institute of Technology

Pasadena, California 91125

Manuscript received 18 March 2009 